\title{
Genome profiling of ERBB2-amplified breast cancers
}

\author{
Fabrice Sircoulomb ${ }^{1 \dagger}$, Ismahane Bekhouche ${ }^{1 \dagger}$, Pascal Finetti ${ }^{1 \dagger}$, José Adélaïde ${ }^{1}$, Azza Ben Hamida ${ }^{1}$, \\ Julien Bonansea', Stéphane Raynaud', Charlène Innocenti', Emmanuelle Charafe-Jauffret ${ }^{1,2,4}$, Carole Tarpin ${ }^{3}$, \\ Farhat Ben Ayed ${ }^{5}$, Patrice Viens ${ }^{3,4}$, Jocelyne Jacquemier ${ }^{1,2}$, François Bertucci ${ }^{1,3,4}$, Daniel Birnbaum ${ }^{1}$, Max Chaffanet $^{1 *}$
}

\begin{abstract}
Background: Around 20\% of breast cancers (BC) show ERBB2 gene amplification and overexpression of the ERBB2 tyrosine kinase receptor. They are associated with a poor prognosis but can benefit from targeted therapy. A better knowledge of these BCs, genomically and biologically heterogeneous, may help understand their behavior and design new therapeutic strategies.
\end{abstract}

Methods: We defined the high resolution genome and gene expression profiles of 54 ERBB2-amplified BCs using 244K oligonucleotide array-comparative genomic hybridization and whole-genome DNA microarrays. Expression of ERBB2, phosphorylated ERBB2, EGFR, IGF1R and FOXA1 proteins was assessed by immunohistochemistry to evaluate the functional ERBB2 status and identify co-expressions.

Results: First, we identified the ERBB2-C17orf37-GRB7 genomic segment as the minimal common 17q12-q21 amplicon, and CRKRS and IKZF3 as the most frequent centromeric and telomeric amplicon borders, respectively. Second, GISTIC analysis identified 17 other genome regions affected by copy number aberration (CNA) (amplifications, gains, losses). The expression of 37 genes of these regions was deregulated. Third, two types of heterogeneity were observed in ERBB2-amplified BCs. The genomic profiles of estrogen receptor-postive (ER+) and negative (ER-) ERBB2-amplified BCs were different. The WNT/ $\beta$-catenin signaling pathway was involved in ERERBB2-amplified BCs, and PVT1 and TRPS1 were candidate oncogenes associated with ER+ ERBB2-amplified BCs. The size of the ERBB2 amplicon was different in inflammatory (IBC) and non-inflammatory BCs. ERBB2-amplified IBCs were characterized by the downregulated and upregulated mRNA expression of ten and two genes in proportion to CNA, respectively. IHC results showed (i) a linear relationship between ERBB2 gene amplification and its gene and protein expressions with a good correlation between ERBB2 expression and phosphorylation status; (ii) a potential signaling cross-talk between EGFR or IGF1R and ERBB2, which could influence response of ERBB2-positive $\mathrm{BCs}$ to inhibitors. FOXA1 was frequently coexpressed with ERBB2 but its expression did not impact on the outcome of patients with ERBB2-amplified tumors.

Conclusion: We have shown that ER+ and ER- ERBB2-amplified BCs are different, distinguished ERBB2 amplicons in IBC and non-IBC, and identified genomic features that may be useful in the design of alternative therapeutical strategies.

\section{Background}

Gene amplification is a frequent alteration in breast cancer $(\mathrm{BC})$ that affects multiple genomic regions [1-3]. One of the most studied amplifications is located in chromosomal region $17 \mathrm{q} 12$ and involves the ERBB2

\footnotetext{
* Correspondence: chaffanetm@marseille.fnclcc.fr

+ Contributed equally

${ }^{1}$ Marseille Cancer Research Center, UMR891 Inserm, Institut Paoli-Calmettes,

Department of Molecular Oncology, Marseille, France

Full list of author information is available at the end of the article
}

gene. $E R B B 2$ encodes a transmembrane tyrosine kinase receptor of the ERBB/EGFR family. ERBB2 is amplified in around $20 \%$ of BCs. The receptor is overexpressed in most amplified cases and in some non-amplified cases as well. This alteration is associated with a poor clinical outcome. BCs with ERBB2 overexpression can benefit from a targeted therapy that uses the humanized monoclonal antibody trastuzumab or the ERBB kinase inhibitor lapatinib $[4,5]$. However, resistance to trastuzumab is
() Biomed Central

(c) 2010 Sircoulomb et al; licensee BioMed Central Ltd. This is an Open Access article distributed under the terms of the Creative Commons Attribution License (http://creativecommons.org/licenses/by/2.0), which permits unrestricted use, distribution, and reproduction in any medium, provided the original work is properly cited. 
frequent [6] and its mechanisms are poorly understood [7], although ERBB2 phosphorylation [8], PTEN and PIK3CA status [9] seem important factors.

$E R B B 2$ gene amplification can be detected by various methods including fluorescence in situ hybridization (FISH) or quantitative PCR [10]. Overexpression of the receptor is detected by immunohistochemistry (IHC) by using the standardized Dako Herceptest. Gene expression studies have shown that $\mathrm{BCs}$ with a specific gene expression signature including ERBB2-overexpression constitute a separate molecular subtype [11-13]. However, a substantial number of breast tumors assigned to the ERBB2 subtype lacks ERBB2 protein expression and/ or ERBB2 gene amplification [14,15] and ERBB2-positive cancers that express estrogen receptor (ER) fall into the luminal subtypes $[11,13,16]$.

Several 17q12-q21 genes are variably coamplified and coexpressed with ERBB2 [17]. This could influence the response to trastuzumab and/or constitute accessory targets for synergistic treatment [18-21]. A better knowledge of ERBB2-amplified BCs may thus help design new therapeutic strategies. To better characterize this particular group of BCs, we used high-resolution array-comparative genomic hybridization $(\mathrm{aCGH})$ and whole-genome DNA microarrays to define the genome and gene expression profiles of 54 BCs with ERBB2 amplification.

\section{Methods}

\section{Breast cancer samples}

Tumor tissues were collected from 340 patients with invasive adenocarcinoma who underwent initial surgery at the Institut Paoli-Calmettes (Marseille, France) between 1987 and 2007 (from a cohort of 2,175 patients with frozen tumor sample) and from a series of 91 Tunisian T4d tumors (TNM, UICC) treated between 1994 and 1998 at the Salah Azaiz Institute (Tunis, Tunisia). Each patient gave informed consent and the study was approved by our institutional review board (also called "COS"). Samples were macrodissected and frozen in liquid nitrogen within 30 minutes of removal. The panel was not made of consecutive tumors but enriched in various forms of BCs. These include inflammatory BCs (IBCs), non-inflammatory BCs (NIBC), very young women BCs (YWBCs, $\leq 35$ years) and older women BCs (OWBCs, $\geq 45$ years).

The 340 tumors were analyzed by high resolution aCGH $244 \mathrm{~K}$ in our previous studies [[3,22], unpublished data]. In all these cases, profiled samples were always collected before any systemic therapy (chemotherapy, hormone or trastuzumab therapy). They corresponded to a tumor surgically removed for NIBCs, and to the diagnostic surgical biopsy for IBCs. A total of 54 (16\%) cases presented amplification of the ERBB2 locus. Features of these ERBB2-amplified tumors are reported in
Additionnal file 1-Table S1. All specimens contained $>60 \%$ of tumor cells (as assessed before RNA extraction using frozen sections adjacent to the profiled samples). IHC data included status for estrogen and progesterone receptors (ER and PR), P53 (positivity cut-off value of $1 \%)$, ERBB2 (0-3+ score, DAKO HercepTest kit scoring guidelines, defined as positive with $3+$ and $2+$ controled by FISH according to ASCO guidelines), and Ki67 (positivity cut-off value of $20 \%$ ).

\section{Cell lines}

Fourteen BC cell lines with ERBB2 amplification (BT474, HCC202, HCC1569, HCC1954, HCC2218, JIMT-1, MDA-MB-361, MDA-MB-453, SK-BR-3, UACC-812, UACC-893, ZR-75-30 [23], SUM-190 and SUM-225 [24]) were grown as recommended by their supplier. These cell lines have been studied by FISH and QPCR and tested for trastuzumab response [8]. Most have also been previously studied by aCGH [25].

\section{DNA and RNA extraction}

DNA and RNA were extracted from frozen samples by using guanidium isothiocynanate and $\mathrm{CsCl}$ gradient, as previously described [26]. RNA integrity was controled on Bioanalyzer (Agilent Technologies).

\section{Array-comparative genomic hybridization (aCGH) and expression data analyses}

Genomic imbalances were determined by aCGH using 244K CGH oligonucleotide microarrays (Hu-244A, Agilent Technologies). Comparison of the results obtained with FISH and aCGH for several gene amplicons demonstrated a perfect agreement between the two techniques [3]. Gene expression data of 51 of the 54 BCs and 4 normal breast (NB) samples (NB1, NB2, NB3 and NB4, representing samples from 4 women and 3 commercial pools of respectively 1, 2 and 4 normal breast RNA, Clontech, Palo Alto, CA) were quantified by using whole-genome DNA microarrays (HG-U133 plus 2.0, Affymetrix). Experiments and data analyses were done as described [3]. Microarray data were deposited in Gene Expression Omnibus (GEO) under the following name: GSE 17907. To identify significant altered regions through the whole genome, we used the GISTIC algorithm to score the Copy-Number Genome across the $54 \mathrm{BCs}$ [27] with a bootstrap procedure to calculate the significance level. Established for each genomic segment, this score takes into account the frequency of gene alterations (amplifications, gains, losses) and their gene copy number level. Expression data, up- and down- regulation were defined using normal breast expression comparison, with a $\mid 2$-fold $\mid$ threshold [3].

The gene expression signature (GES) associated with $\mathrm{ER}+$ and ER-ERBB2-amplified BCs was obtained using 
Signal-to-Noise Ratio (SNR) and its significance was assessed using resampling with 100 permutations as described [28]. Unsupervised analysis was done with the Cluster program using $\log _{2}$-transformed data [29]. Expression data were median-centred on genes. For aCGH analysis, we evaluated robustness of clusters using multiscale bootstrap resampling; the robustness of each cluster was estimated with the R-package pvclust [30] using Ward's agglomerative method, Euclidean distance and 1000 bootstrap replications as parameters. Pvclust provides AU (approximately unbiased) p-values computed by multiscale bootstrap resampling. Cluster agglomerative parameters were centroid-linkage for expression [13]. Pearson correlation was used as similarity metrics for both of them.

Details concerning statistical methods are given in Additionnal file 2.

\section{Pathway/network analysis}

The biologic relevance of the data was estimated using the Ingenuity Pathway Analysis (IPA) software (Ingenuity Systems) [31]. This functional annotation and network-mapping tool enables the discovery, visualization, and exploration of biologically and therapeutically relevant networks of gene interactions from the experimental data. Focus genes were imported using their Entrez Gene ID to be mapped to the Ingenuity database. The identified genes were mapped to genetic networks available in the Ingenuity database and were then ranked by the probability that a collection of genes equal to or greater than the number in a network could be achieved by chance alone. Confidence level of $99.9 \%$ was chosen as cut-off. Ingenuity ${ }^{\bullet}$ software [31] was then used to identify canonical pathways and networks.

\section{Immunohistochemistry (IHC)}

IHC was done using commercially available mouse monoclonal antibodies directed against human ERBB2, FOXA1, phosphorylated ERBB2 (pERBB2), IGF1R, and EGFR (Additionnal file 1-Table S2). The HercepTest (DAKO) is directed against the intracellular region of ERBB2 with high sensitivity; TAB250 anti-ERBB2 recognizes with high specificity but low sensitivity the extracellular region of the receptor [10]. Phosphorylated ERBB2 status was assessed using monoclonal mouse anti-human HER2-pY-1248 with CSA II biotin-free tyramide signal amplification system (DakoCytomation) as described [8].

IHC was done on 5- $\mu$ m sections of tissue fixed in alcohol formalin for 24 hours and embedded in paraffin as described [32], using $\mathrm{LSAB}^{\mathrm{R}} 2$ kit in the autoimmunostainer (Dako Autostainer). According to a previous study [33], effects of fixation in this condition time would not affect the immunohistochemical detection of hormone receptors in breast cancer. The optimal titer for each antibody (except for HercepTest and G11 directed against ERBB2 and IGF1R, Additionnal file 1Table S2) was established based on negative and positive controls. In addition, the dilution took into account the expected topography of the immunostaining (nucleus, cell membrane, and cytoplasm). After staining, slides were evaluated by two pathologists (J.J. and E.C.J.). Results for EGFR, pERBB2, FOXA1 and IGF1R status were scored by the quick score (QS) [32], taking into account the percentage (P) and intensity (I) of immunostaining $(\mathrm{QS}=\mathrm{P} \times \mathrm{I}$ varies from 0 to 300$)$ except for ERBB2 status (defined with ERBB2 TAB250 or HercepTest kit), which was evaluated with the Dako scale (0-3+, HercepTest kit scoring guidelines). Discrepancies were resolved under multiheaded microscope. We chose a uniform and clear cutoff value of QS $>0$ for all antibodies, except for ERBB2 where the HercepTest scale was used: negative $0-1+$ and positive $2+$ and $3+$.

\section{Statistical analyses}

Associations of EGFR, ERBB2, pERBB2, FOXA1 and IGF1R expression with histoclinical features were assessed with Spearman's rank-correlation test or Mann-Whitney U test, as appropriate. Overall survival (OS) time was defined as the period from the date of starting first-line chemotherapy until the date of death from any cause or until the date of the last follow-up, at which point data were censored. Metastasis-free survival (MFS) was defined by the time interval between the diagnosis of $\mathrm{BC}$ and a distant metastasis. Metastasis-free patients were right censored at the date of the last follow-up, death, recurrence of local or regional disease, or development of a second primary cancer. Kaplan-Meier method was used to plot OS or MFS curves according to IHC results, and the significance of differences was assessed with the log-rank test. Univariate and multivariate Cox proportional hazard models were used to estimate the relations of protein expressions and clinical characteristics to OS. All reported p-values were twosided, and the level of significance was set at $\mathrm{p}<0.05$. Variables for multivariate analysis were selected by means of a forward stepwise approach, using a significance level of $p<0.10$ for entering into or remaining in the model. All analyses were done with the software package StatView, version 5.0 (SAS Institute, Inc.).

\section{Results}

\section{Characterization of ERBB2-amplified BCs and cell lines}

From our previous aCGH studies [[3,8,22], unpublished data], we identified 54 tumors and 14 cell lines exhibiting regional 17q12-q21-amplification (with a threshold $\log _{2}$ ratio $>1$ ) centered on ERBB2 (Additionnal file 3Figure S1A-C and S1D, respectively). The ERBB2 
frequency of amplification (16\%, 54/340) observed in our panel was close to the frequency values obtained in previous studies [34-37].

By using two different threshold values $\left(\log _{2}\right.$ ratio $>|0.5|$, and $|1|)$, we distinguished low-level CNAs, which can result from aneuploidy, from high-level CNAs, which result from focal amplification or deletions of chromosome regions. Using the GISTIC algorithm, the 17q12-q21-amplicon exhibited the highest score index because it was the most frequently amplified with the highest level of amplification. In agreement with previous reports [1,37], the frequency plot analysis showed additional regions of recurrent gene copy number gains and amplification including 1q22-24, 8p12, 8q21-24, 11q13, 17q, 20q13.3 regions (Figure 1).

The histoclinical features and molecular subtypes of the 54 ERBB2-amplified BCs are listed in Additionnal file 1-Table S1. They contained 20 IBC and 34 NIBC as well as 10 and 21 primary breast tumors of young $(\leq 35$ years) and older women ( $\geq 45$ years) (YWBC and OWBC, respectively). The presence of IBC samples among the $54 E R B B 2$-amplified tumors reflects the fact that IBCs do comprise a large proportion of ERBB2 cancers. The ERBB2-amplified cases were mainly ductal tumors with pathological grade 3, high expression of ERBB2, TP53 and high Ki67 proliferative index. Moreover, $53 \%$ and $6 \%$ of the ERBB2-amplified BCs were of ERBB2-like and luminal B subtypes, respectively.

\section{Heterogeneity of ERBB2-amplified tumors}

We first established the unsupervised hierarchical clustering of the 54 samples and the 225,388 aCGH oligonucleotide probes (excluding $\mathrm{X}$ and $\mathrm{Y}$ chromosomes) (Figure 1). The samples were separated in two groups (I and II) of 26 and 28 samples, respectively. Histoclinical features were compared between the two groups except for TP53 and Ki67 status because of a too low number of informed samples. For the other histoclinical features, no difference was observed between the two groups except for ER expression $(\mathrm{p}<0.05)$ (Additionnal file 1-Table $\mathrm{S} 3$ ). These results showed heterogeneity of ERBB2-amplified tumors with at least two categories, ER- and ER+.

ER and PR status were not available for seven samples (Figure 1). To evaluate the robustness of the clusters, we established the hierarchical clustering without these seven samples (data not shown) and compared it with the clustering analysis including them. The results showed a similar distribution (accuracy $=98 \%$ ) and confirmed that ER+ and ER-ERBB2-amplified breast cancers are different (Fisher exact's test, $\mathrm{p}=0.019$; O.R. $=4.39$ ).

We focused on the profiles of chromosome 17 long arm (Figure 2). Unsupervised hierarchical clustering of the 54 samples and the 5,574 oligonucleotide probes covering $17 \mathrm{q}$ (Figure 2) separated the samples in two groups (I and II) of 28 and 26 samples, not different with respect to histoclinical features. This separation was influenced by the amplicon size and the gene copy number associated with the multiple amplifications on 17q. The GISTIC score based on the calculation combining CNA frequency and gene amplification level showed that only the 17q12-q21 (pink box) amplicon centered on the ERBB2 locus was significant ( $\mathrm{p}<0.001$ ) (Figure 2).

By next focusing on a smaller interval comprised between AATF and STAT3 genes (Figure 3), we found that the $E R B B 2$-amplicon size varied within a region delimited by DDX52 and KRT40 genes from centromere to telomere, respectively (Figure 3). Hierarchical clustering of the 54 samples and the 650 oligonucleotide probes covering this region separated the samples in two groups (I and II) of 20 and 34 samples, respectively. The ERBB2-amplicon size was larger in group I than in group II. As shown in Figure 3, IBCs had a smaller amplicon than NIBCs, and hormonal receptor negative tumors (ER- and PR-) a smaller amplicon than hormonal receptor positive tumors $(E R+$ and/or $P R+)(p=$ 0.04 and $\mathrm{p}=0.03$, respectively) (Additionnal file 1Table S4). Group II contained twice more IBC tumors than group I. IBCs have a poorer prognosis than NIBCs. The absence of 5-year MFS difference between the two groups suggested that the presence of the $E R B B 2$-amplicon influences the NIBC phenotype and generates in NIBCs the same pejorative evolution as that observed in IBCs.

Taken together, our results identified two types of heterogeneity within $E R B B 2$-amplified tumors, i.e. with respect to ER status and to IBC/NIBC clinical forms.

To evaluate the potential impact of the ER status on the amplicon size changes linked to IBC and NIBCs, we repeated the analysis using ER- and and ER+ gradematched IBC and NIBC samples. The number of grade 1 and 2 tumors ER- and ER+ IBC and NIBC samples was too low to be compared in such analysis. Therefore, 21 samples of grade $3 \mathrm{ER}-\mathrm{IBC}(\mathrm{N}=10)$ and $\operatorname{NIBC}(\mathrm{N}=$ 11) were compared (data not shown). The results showed that grade 3 ER- IBCs have a smaller ERBB2amplicon than grade 3 ER- NIBCs. A similar result was obtained with grade $3 \mathrm{ER}+\mathrm{IBC}(\mathrm{N}=7)$ and $\operatorname{NIBC}(\mathrm{N}=$ 6) samples (data not shown). These results suggest that the size of the ERBB2 amplicon is smaller in IBC than in NIBC and that this is independent of the ER status.

\section{Size, core and magnitude of the ERBB2-amplicon}

To better define the ERBB2-amplicon, we extracted the data associated with gene copy number amplification for the $54 \mathrm{BCs}$ and the 14 cell lines within the region comprised between AATF and STAT3 (Additionnal file 1 -Table S4). For each of the 54 samples, we precisely 


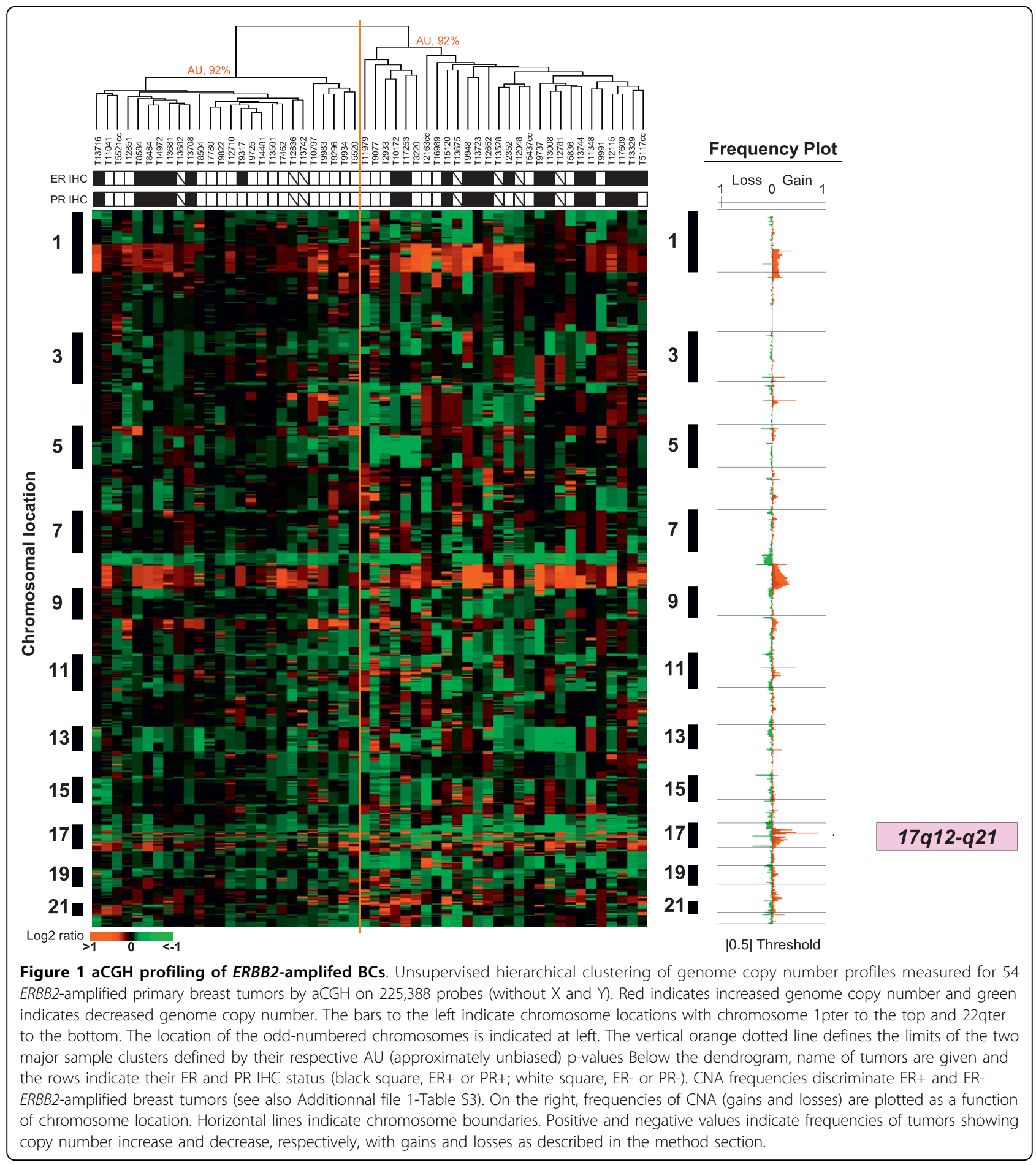

defined centromeric and telomeric borders and the size of the ERBB2-amplicon by measuring the $\log _{2}$ ratio for each oligonucleotide of the region (Additionnal file 1Table S5). The amplicon borders were defined as first genes targeted by amplification at the centromeric and telomeric locations of the ERBB2-amplicon. PLXDC1, FBXL20, MED1, CRKRS and STARD3 were identified as frequent centromeric borders and IKZF3, PSMD3, THRA, WIPF2, CDC6 and RARA as frequent telomeric borders. Overall, CRKRS and IKZF3 were the most frequent centromeric and telomeric borders, respectively.

The ERBB2-C17orf37-GRB7 genomic segment was systematically amplified in all $E R B B 2$-amplified samples and constitutes the core of the amplicon. 


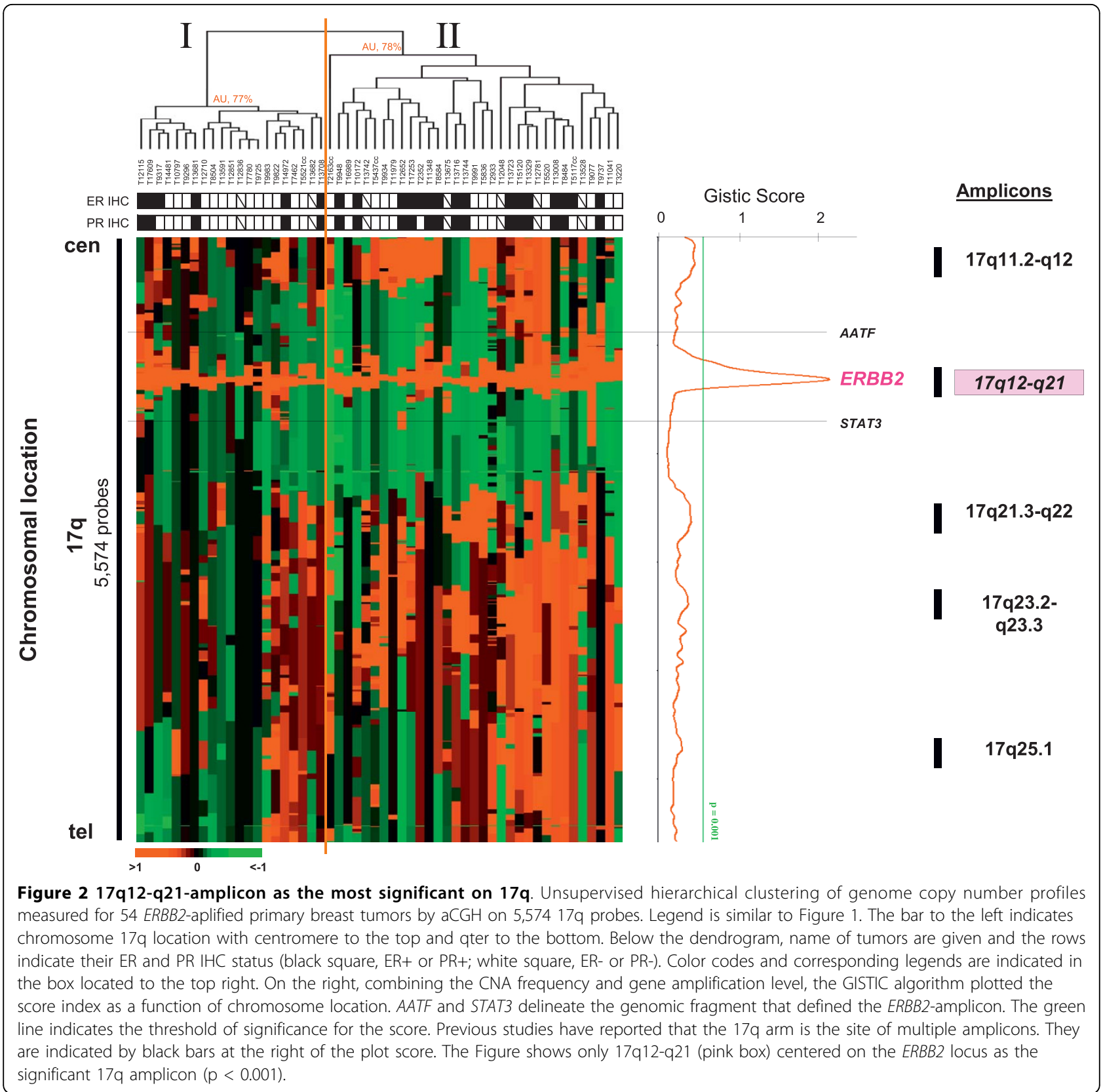

Finally, we evaluated the ERBB2 copy number averages by aCGH in $22 \mathrm{ER}+, 25 \mathrm{ER}-, 20 \mathrm{IBC}$ and 31 NIBC cases. They were equal to 11.2, 10.7, 10.5 and 11.8 respectively, indicating that the magnitude of the amplification is not different in the different entities.

\section{Chromosomal regions altered by CNAs in ERBB2-amplified tumors}

To identify other regions frequently targeted by CNA in the ERBB2-amplified tumors, we used the GISTIC algorithm. In addition to the 17q12-q21 amplicon, the score index pointed to 17 other regions affected by CNAs ( $<$ 0.001) (Additionnal file 1-Table S6A) including six regions of gain (1p36.33-p36.32, 4q13.3, 8q23.3-q24.21, 11q13.5-q14.1, 14q11.1-q11.2, 19q12) and eleven regions of loss $(4 \mathrm{p} 16.3,7 \mathrm{p} 22.3,8 \mathrm{p} 23.3-$ p23.2, 8p11.23-p11.22, 9q34.3, 10q26.3, 11p15.5, $14 \mathrm{q} 32.33,15 \mathrm{q} 11.2,16 \mathrm{p} 13.3,19 \mathrm{p} 13.3)$. Including the $17 q 12-q 21$ genes, a total of 282 genes were targeted (Additionnal file 1-Table S6A). Regions 4q13.3, 8q23.3q24.21, 11q13.5-q14.1, 14q11.1-q11.2, 17q12-q21.2, $19 \mathrm{q} 12$ were also amplified. 


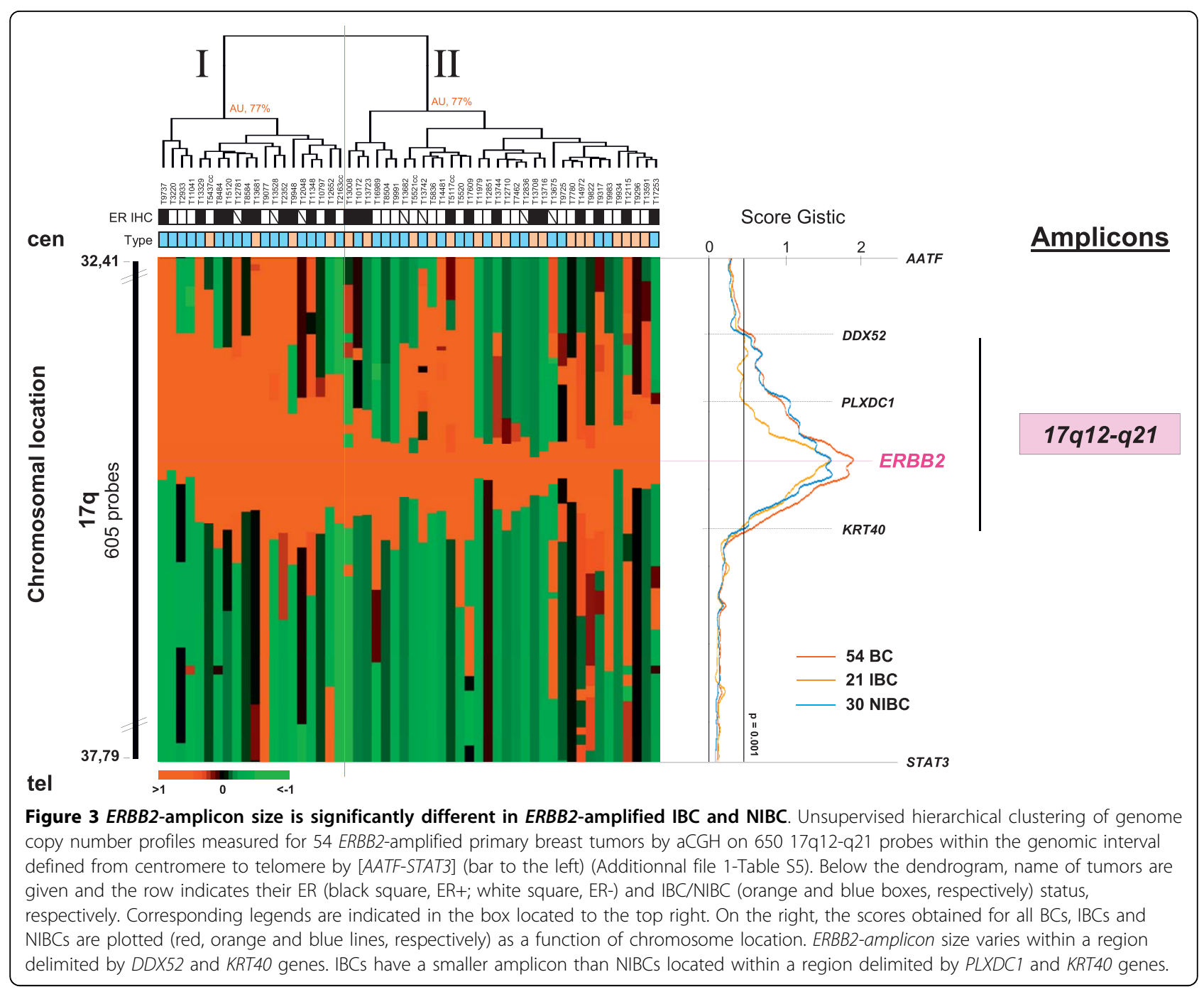

\section{Correlation between mRNA expression and CNA in ERBB2- amplified tumors}

To identify genes whose expression levels were modified in proportion to CNA, we combined aCGH and RNA expression data for 51 samples in integrated analyses, as described [3]. Within altered chromosomal regions, relations between gene expression and CNA level were assessed by Pearson correlation test $(\mathrm{p}<0.01)$ on genes for which variations (at both level, gene CNA and deregulated expression), were explained by more than $10 \%$ of tumors. The cut-off of $10 \%$ was arbitrary defined to increase the robustness of the candidate gene selection. We then identified 1 and 36 genes whose expression levels were downregulated and upregulated in proportion to DNA copy number losses and gains (or amplification), respectively (Additionnal file 1-Table S6A, genes written in bold) $(\mathrm{p}<0.01)$. They were located in 8p23.3-p23.2 (C8orf68), 8q23.3-q24.21
(C8orf53, MAL2, LOC286052, SQLE, KIAA0196), 11q13.5-q14.1 (RSF1, INTS4, KCTD21), 17q12-q21.2 (DDX52, MRPL45, SOCS7, ARHGAP23, SNIP, MLLT6, CISD3, PCGF2, PSMB3, PIP4K2B, CCDC49, LASP1, LOC642808, CACNB1, LOC90110, FBXL20, MED1, CRKRS, STARD3, PERLD1, ERBB2, C17orf37, GRB7, RAPGEFL1, WIPF2, CDC6, RARA), and 19q12 (CCNE1) regions, respectively. Some genes with correlation between CNA and mRNA expression (Additionnal file 1-Table S6A) have been found in previous studies $[1,38]$.

In the 17q12-q21.2 amplicon, which exhibited the highest frequency (Additionnal file 1-Tables S6A-S6B), amplifications combined to the upregulated gene expression of CRKRS (71\%), STARD3 (82\%), PERLD1 (86\%), ERBB2 (92\%), C17orf37 (84\%) and GRB7 (86\%) were the most frequent (Additionnal file 1-Tables S6A-S6B). This high correlation between gene amplification and gene expression is in agreement with a previous report [39]. 


\section{Integrated genome analysis of ER- and ER+ ERBB2- amplified tumors}

Supervised genome profile analysis identified 43 altered (gains and losses defined with a threshold value of $\log _{2}$ ratio $>|0.5|$ ) genes with a frequency different in ER- and $\mathrm{ER}+$ ERBB2-amplified BCs (Fisher exact test $\mathrm{p} \leq 0.05$ and False Discovery-Rate (FDR) corrected, Benjamini and Hochberg FDR inferior to 25\%) (Additionnal file 1Table S7A and Additionnal file 2-). Unfortunately, these 43 altered genes could not be validated in a separate cohort of BCs because no high resolution aCGH data ( $\geq 20,000$ oligos) including ER information were available among public data.

Gains targeting GDPD4, PAK1, CLNS1A genes at $11 \mathrm{q} 13.5$ were associated with ER-ERBB2-amplified BCs (Table 1). In ER+ ERBB2-amplified BCs, 40 genes were altered by (i) copy number gain at $8 \mathrm{p} 11.23$ and 8q23.3-q24.21 (27 genes), (ii) amplification at 8q24.13 and 17q12-q21.1 (5 genes), (iii) both gain and amplification at 8q24.13 (2 genes), and (iv) losses or deletions at $1 \mathrm{p} 31.33,1 \mathrm{p} 36.32,4 \mathrm{p} 16.3$ and $11 \mathrm{p} 15.5$ (6 genes) (Table 1$)$. Only genes $(\mathrm{N}=17)$ targeted by CNA in ER $+E R B B 2$ amplified $\mathrm{BCs}$ were sites of genomic variation (12 by copy number variation [CNV], 4 by insertion or deletion [InDel] and 1 by inversion), respectively (Table 1).

When aCGH and RNA data were combined (Additionnal file 1-Table S7A), TRPS1 and PVT1 were found associated with ER+ERBB2-amplified tumors (Table 1).

\section{Gene expression and canonical pathways of ER- and ER+ ERBB2-amplified tumors}

We established the gene expression profiles of 51 of the 54 samples. Hierarchical clustering did not distinguish ER-ERBB2-amplified BCs from ER+ERBB2-amplified $\mathrm{BCs}$ (Additionnal file 4-Figure S2). The $51 \mathrm{BCs}$ were separated in two groups (I and II) of 25 and 26 cases, respectively. No difference in ER protein expression (as defined by $\mathrm{IHC}$ ) was observed between the two groups $(\mathrm{p}=0.25)$ (Additionnal file 1-Table S7B). Group II contained more IGF1R-expressing tumors (as defined by IHC) and normal-like tumors than group I.

Supervised analysis of the 51 samples showed that 402 genes (corresponding to 638 probe sets) were differentially expressed in ER- and ER+ERBB2-amplified tumors (SNR analysis with FDR $<0.1 \%$ ) (Figure 4 ). They included 257 genes upregulated in ER- ERBB2-amplified tumors and 145 upregulated in ER+ERBB2-amplified tumors (corresponding to 366 and 272 probe sets, respectively) (Additionnal file 1 -Table $\mathrm{S} 7 \mathrm{C}$ ). GATA3, ESR1, TFF1, TFF3 and ERBB4 were upregulated, whereas IGF2R, GATA6, EGFR and TGFA were downregulated in ER+ERBB2-amplified tumors.
Using the Ingenuity software, canonical pathways were defined as associated with either ER- or ER+ERBB2amplified tumors $(\mathrm{p}<0.05)$ (Additionnal file 1-Table S7D and Additionnal file 5-Figure S3). Genes coding for proteins involved in $\mathrm{WNT} / \beta$-catenin signaling pathway, aryl hydrocarbon receptor signaling (cell cycle and apoptosis or nuclear receptor signaling), LPS/IL-1 mediated inhibition of RXR function (nuclear receptor signaling) as well as various metabolic pathways (i.e. Nicotinate and nicotinamide, galactose, Inositol Phosphate, $\beta$-Alanine) were upregulated in ER-ERBB2-amplified tumors $(\mathrm{p}<0.05)$. In contrast, among genes downregulated in ER- ERBB2-amplified tumors ( $<<0.05)$, some coded for proteins involved in endothelin-1 signaling, nitric oxide signaling in the cardiovascular system (both associated with cardiovascular signaling pathways), NRF2-mediated oxidative stress response (cell stress and injury pathway), synaptic long term depression, neuropathic pain signaling in dorsal horns neurons, mechanisms of viral exit from host cells and other metabolic pathways.

\section{Chromosomal regions altered by CNAs in NIBC and IBC ERBB2-amplified tumors}

To identify regions frequently targeted by CNA in IBC and NIBC ERBB2-amplified tumors, we used the GISTIC algorithm. The score index pointed to 4 gained or amplified regions (8q23.3, 17q11.1-q11.2, 17q12-q21.2 and 17q21.32-q21.33) in NIBCs and 7 gained or amplified regions (8q24.11-q24.12, 8q24.13, 8q24.13-q24.21, 17q11.2, 17q12-q21.2, 17q21.33 and 19q12) in IBCs (p < 0.001) (Additionnal file 1-Table S7E). A total number of 172 and 113 genes were targeted in NIBC and IBC populations, respectively. Among them, 50 genes were commonly found altered (in bold in Additionnal file 1-Table $\mathrm{S7E}$ ) in the two populations. The number of genes associated with the 17q12-q21 amplicon was lower in IBC than in NIBC in agreement with the size difference of the $E R B B 2$-amplicon between the two populations.

\section{Gene expression differences between IBC and NIBC ERBB2-amplified tumors}

We compared the expression of genes targeted by the 17q12-q21-amplicon in IBCs and NIBCs. SNIP (p = $0.0002), M L L T 6(\mathrm{p}=0.0072), C I S D 3(\mathrm{p}=0.0111)$, PCGF2 ( $\mathrm{p}=0.0067)$, PSMB3 $(\mathrm{p}=0.0029), P I P 4 K 2 B(\mathrm{p}=$ 0.0126), FBXL20 ( $\mathrm{p}=0.0324)$, STARD3 $(\mathrm{p}=0.0318)$, $G R B 7(\mathrm{p}=0.0244)$ and $R A R A(\mathrm{p}=0.0201)$ were downregulated in $E R B B 2$-amplified IBCs compared to ERBB2-amplified NIBCs. SQLE (8q24.13) (p = 0.0268) and RSF1 (11q13.5) ( $\mathrm{p}=0.0067)$ were upregulated in ERBB2-amplified IBCs.

To better understand the mechanisms associated with gene expression deregulation of these candidates in IBC 
Table 1 Genes altered by CNA with a frequency significantly different in ER+ and ER- ERBB2-amplified tumors

\begin{tabular}{|c|c|c|c|c|}
\hline ER status of ERBB2-amplified tumors & Targeted by gene CNA & Altered genes & Location & CNV, Type\# \\
\hline \multirow[t]{3}{*}{ ER- } & gain & GDPD4 & $11 q 13.5$ & \\
\hline & & PAK1 & & \\
\hline & & CLNS1A & & \\
\hline \multirow[t]{40}{*}{ ER+ } & gain & ADAM5P & $8 p 11.23$ & Variation_1197, CNV \\
\hline & & ADAM3A & & Variation_1779, CNV \\
\hline & & TRPS1* & $8 q 23.3$ & Variation_42116, InDel \\
\hline & & BC040336 & & \\
\hline & & EIF3H & & \\
\hline & & $A L 713790$ & $8 q 24.11$ & \\
\hline & & SLC30A8 & & \\
\hline & & MED30 & & \\
\hline & & SAMD12 & $8 q 24.12$ & Variation_3145, CNV \\
\hline & & FAM91A1 & $8 q 24.13$ & \\
\hline & & C8orf54 & & \\
\hline & & C8orf78 & & \\
\hline & & BC015129 & & \\
\hline & & TMEM65 & & Variation_52365, CNV \\
\hline & & CR933665 & & \\
\hline & & RNF139 & & Variation_28765, InDel \\
\hline & & TATDN1 & & \\
\hline & & MTSS1 & & Variation_43549, CNV \\
\hline & & LOC157381 & & \\
\hline & & SQLE & & Variation_34021, InDel \\
\hline & & KIAA0196 & & \\
\hline & & NSMCE2 & & Variation_41128, Indel \\
\hline & & TRIB1 & & \\
\hline & & BC038572 & $8 q 24.21$ & \\
\hline & & FAM84B & & Variation_37296, Inversion \\
\hline & & PVT1* & & Variation_8615, CNV \\
\hline & & $B C 009730$ & & \\
\hline & amplification & C8ORFK23 & $8 q 24.13$ & \\
\hline & & LOC650095 & & \\
\hline & & LOC90110 & $17 q 12$ & Variation_5006, CNV \\
\hline & & $F B X L 20$ & & CNVVariation_5006, CNV \\
\hline & & CASC3 & $17 q 21.1$ & \\
\hline & gain or amplification & ZNF572 & $8 q 24.13$ & \\
\hline & & AK093407 & & \\
\hline & loss or deletion & SAMD11 & $1 \mathrm{p} 36.33$ & Variation_30362, CNV \\
\hline & & AGRN & & Variation_2294, CNV \\
\hline & & GNB1 & & Variation_3276, CNV \\
\hline & & AK128532 & $1 p 36.32$ & \\
\hline & & RNF212 & $4 p 16.3$ & Variation_30190, CNV \\
\hline & & B4GALNT4 & $11 \mathrm{p} 15.5$ & Variation_29880, CNV \\
\hline
\end{tabular}

*TRPS1 and PVT1 gene expression was in proportion to their CNA

\# The information about the presence of CNV and the type of genomic variations (CNV, InDel, inversion...) was extracted from hg17 and hg18.

and NIBC we looked in detail at their genomic alterations. Among the 10 genes downregulated in ERBB2amplified IBCs compared to ERBB2-amplified NIBCs, we noted that SNIP and RARA were gained or amplified in NIBCs but not in IBCs. MLLT6, CISD3, PCGF2, PSMB3, PIP4K2B, FBXL20, STARD3, GRB7 were gained or amplified in both populations. This suggests that downregulation of these 10 genes in IBC could be driven by epigenetic mechanisms differentially regulated in the two populations. Among the 2 genes upregulated in $E R B B 2$-amplified IBCs compared to ERBB2-amplified NIBCs, SQLE (8q24.13) was gained or amplified in IBCs 


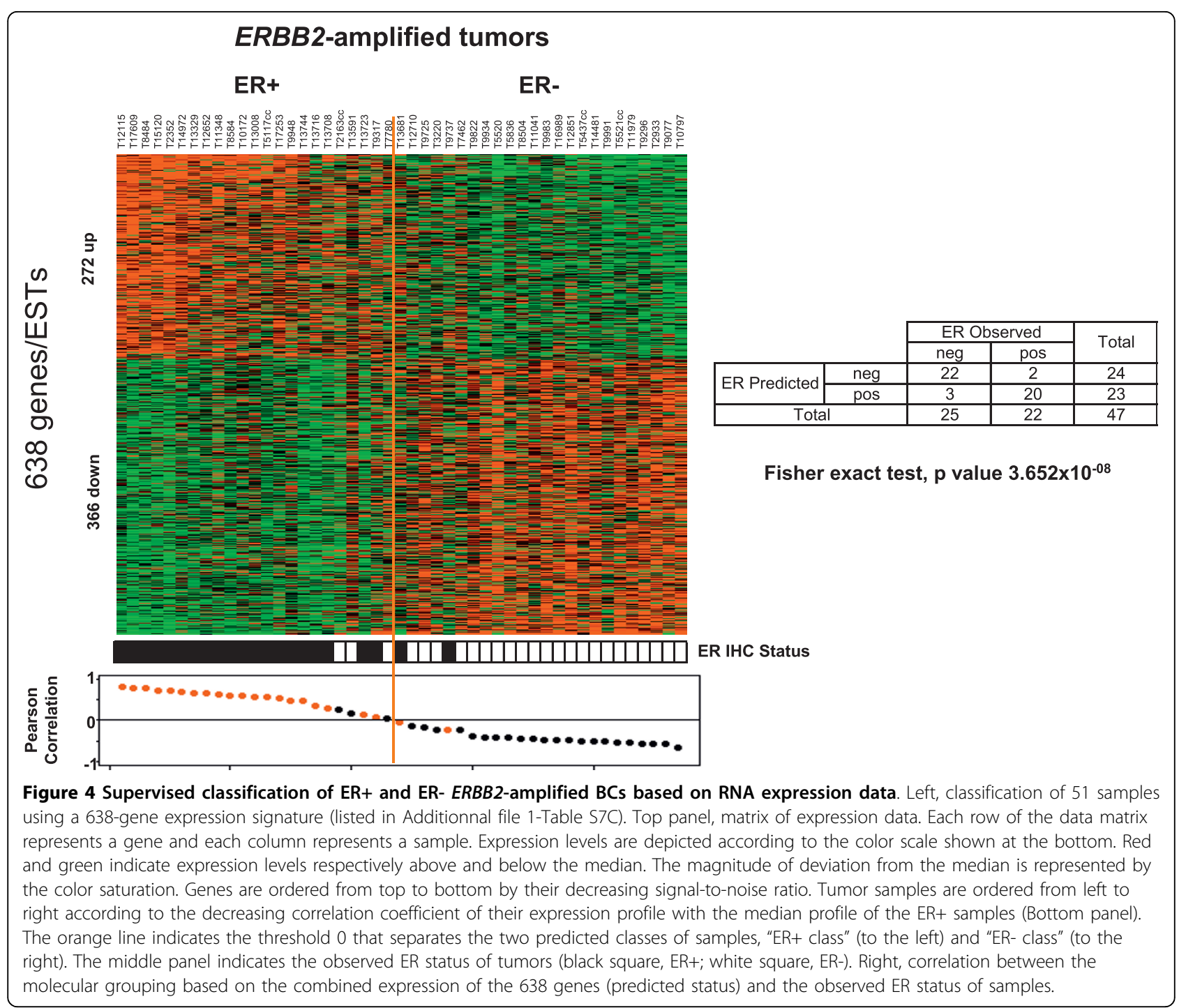

but not in NIBCs while RSF1 (11q13.5) was not targeted by CNA in the two populations. This suggests that the upregulation of $S Q L E$ associated with gain or amplification could be a specific oncogenic mechanism in IBC whereas the upregulation of RSF1could be explained by others mechanisms such as hypomethylation of its promoter.

\section{ERBB2 amplification, gene expression, protein expression and phsophorylation}

ERBB2 status was assessed by IHC. First, we used the HerceptTest and the TAB250 antibodies to evaluate the ERBB2 expression but also to compare their detection in relation with the ERBB2-amplification. Therefore, using HerceptTest on 40 ERBB2-amplified BCs (Figure 5), 97.5\% (39/40) of the samples were ERBB2-positive (Additionnal file 1-Tables S7-S8A). They were classified 2+ (1 ERBB2-like, 1 luminal A, 2 basal and 1 normal- like) and 3+ (15 ERBB2-like, 2 luminal A, 2 luminal B, 2 basal, 6 normal-like, 7 not assigned). Only one (luminal A) was $0+$ (Additionnal file 1-Table S8). TAB250 on 35 $E R B B 2$-amplified $\mathrm{BCs}$ detected 23 positive samples (66\%) (Additionnal file 1-Tables S8-S9A). A total of 35 tumors were analyzed with both HercepTest and TAB250. Among the 23 samples positive for TAB250, all (100\%) were also HerceptTest positive (Additionnal file 1-Table S8). Conversely, among the 12 tumors negative for TAB250, only one was HerceptTest negative (Additionnal file 1-Table S8).

$E R B B 2$ copy number averages evaluated by aCGH in tumors positive with HerceptTest $(\mathrm{N}=39)$, TAB250 $(\mathrm{N}=23)$ or both were equal to $11.3,13.3$ and 13.3 respectively (Additionnal file 1 -Table S8). Tumors negative for HerceptTest $(\mathrm{N}=1)$, TAB250 $(\mathrm{N}=12)$ or both were equal to 8.8, 7.8 and 8.8, respectively. Among samples positive with both HerceptTest and TAB250, 41\% 


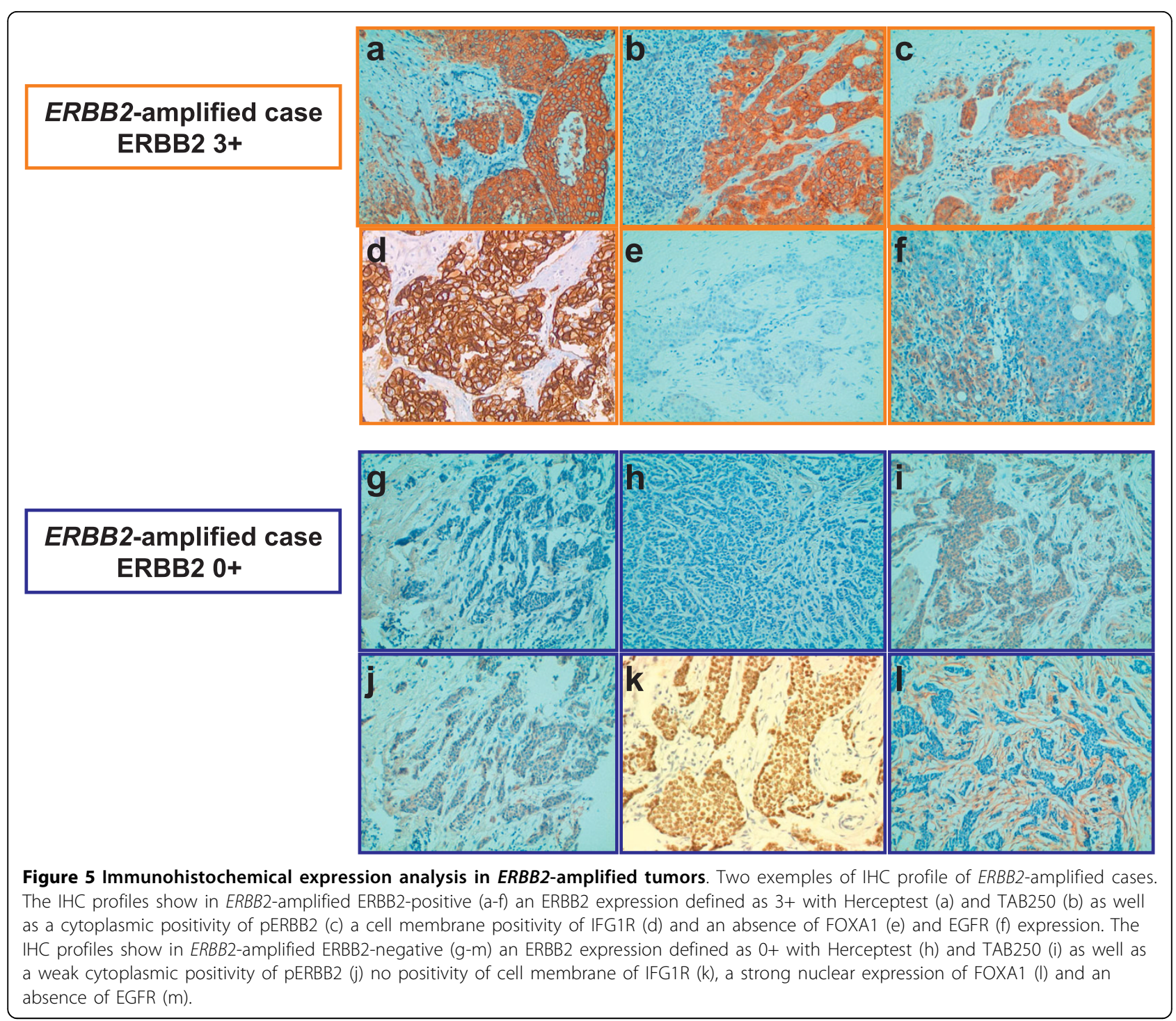

(16/39) and 48\% (11/23) were subtyped as ERBB2-like, respectively. Similarly, among samples positive with both HerceptTest and TAB250, 5\% (2/39) and 4\% (1/23) were subtyped as luminal $B$, respectively. Taken together, these results suggest a linear relationship between $E R B B 2$ gene amplification and its gene and protein expressions for almost half of ERBB2-amplified samples. This relationship was not perfect for $4 / 12$ amplified samples negative with TAB250 were ERBB2like, respectively. However, we noted that they were all $3+$ with HerceptTest. The only ERBB2-amplified sample negative with HerceptTest (T11348) was luminal A. Unfortunately, no sufficient material (T11348) associated with a correct morphology was available to confirm its $E R B B 2$ amplification status by using silver in situ hybridization (SISH, Ventana). The IHC pattern of this sample showing also FOXA1 positivity was in agreement with its luminal A phenotype $[40,41]$, suggesting that no mismatching had occurred for this case.

The expression of pERBB2 could help predict clinical response of ERBB2-positive BCs to trastuzumab or lapatinib $[8,42,43]$. pERBB2 status was evaluated by IHC on 22 ERBB2-amplified samples (Figure 5) and was detected in 17/22 (Additionnal file 1-Tables S8-S9A). Among the 17 samples, $17(100 \%)$ and 14 (82\%) were also HerceptTest and TAB250 positive, respectively. This result suggests a good correlation between ERBB2 expression and phosphorylation status (Table 2).

\section{IGF1R and EGFR expression in ERBB2-amplified tumors}

Expression levels of insulin-like growth factor type 1 receptor (IGF1R), epidermal growth factor receptor (EGFR), and ERBB2 have been linked to clinical outcome in breast and other solid tumors [44]. We 
Table 2 Co-expression frequency and association between protein expressions

\begin{tabular}{ll}
\hline Protein combinations & $\begin{array}{l}\text { Co-expression* } \\
\text { N (\%) }\end{array}$ \\
\hline pERBB2/ERBB2 & $81 \%(17 / 21)$ \\
IGF1R/ERBB2 & $24 \%(7 / 29)$ \\
IGF1R/pERBB2 & $14 \%(2 / 14)$ \\
EGFR/ERBB2 & $33 \%(12 / 36)$ \\
EGFR/pERBB2 & $41 \%(7 / 17)$ \\
IGF1R/EGFR & $11 \%(1 / 9)$ \\
IGF1R and EGFR/ERRB2 & $3 \%(1 / 29)$ \\
IGF1R and EGFR/pERBB2 & $0 \%(0 / 14)$ \\
FOXA1/ERBB2 & $67 \%(14 / 21)$ \\
FOXA1/pERBB2 & $71 \%(12 / 17)$ \\
\hline
\end{tabular}

${ }^{*}$ Co-expression means that tumors were positive for both factors. ${ }^{\dagger}$ Expression scores evaluated according to scales defined in material and methods to examine correlations.

extended our IHC analysis to define a potential impact of IGF1R and EGFR protein expression in ERBB2-amplified patients.

IGF1R status was assessed in 30 ERBB2-amplified BCs for which ERBB2 IHC status had been determined (Figure 5). Seven (23\%) tumors expressed IGF1R (Additionnal file 1-Tables S8-S9A); all of them also expressed ERBB2 (all HerceptTest 3+). Similarly, EGFR status was assessed in 37 ERBB2-amplified BCs for which ERBB2 status was established. Twelve (32\%) tumors expressed EGFR (Additionnal file 1-Tables S8-S9A); all of them expressed ERBB2 (HerceptTest: $93+$ and $32+$ ). IGF1R/ EGFR/ERBB2 coexpression was rarely observed (1/29) while IGF1R/ERBB2 and EGFR/ERBB2 coexpression was observed in $24 \%(7 / 29)$ and $33 \%(12 / 36)$ of cases, respectively (Table 2). IGF1R/EGFR/pERBB2 coexpression was never observed $(0 / 24)$ while IGF1R/pERBB2 and EGFR/pERBB2 coexpression was observed in 14\% $(2 / 14)$ and $41 \%(7 / 17)$, respectively (Table 2$)$. These results are in agreement with the signaling cross-talk described between EGFR family members and IGF1R in maintaining the malignant phenotype [45].

\section{FOXA1 is frequently coexpressed with ERBB2 in ERBB2- amplified tumors}

Forkhead transcription factor FOXA1 is involved in mammary tumorigenesis and may be involved in a cross-talk between hormonal receptors and ERBB2 [41]. To define a potential impact of FOXA1 expression in $E R B B 2$-amplified BCs, FOXA1 status was assessed by IHC in 22 ERBB2-amplified BCs for which ERBB2 IHC status had been determined (Figure 5). Fifteen (68\%) tumors expressed FOXA1 (Additionnal file 1-Tables S8S9A). FOXA1 expression was observed in $67 \%(14 / 21)$ of ERBB2-positive tumors. In details, 1 (luminal A) and 14 tumors (1 luminal B, 9 ERBB2-like, 3 normal-like and 1 not assigned) were classified as $0+$ and $3+$, respectively. This result is in agreement with a recent study showing that FOXA1 was expressed in all ERBB2-positive breast cancer cell lines [46]. FOXA1 expression was observed in 71\% (12/17) of pERBB2-tumors (Table 2).

\section{Clinical features and protein expression analysis of ER+ and ER- ERBB2-amplified BCs}

We finally compared clinical features and EGFR, FOXA1, ERBB2, pERBB2 and IGF1R protein expression in ER+ $(\mathrm{N}=22)$ and ER- $(\mathrm{N}=25)$ ERBB2-amplified tumors (Additionnal file 1-Table S9B). Compared to ER+ cases, ER- cases were all PR-negative $(\mathrm{p}<0.001)$, more often EGFR-positive $(\mathrm{p}<0.05)$ and ERBB2-like. ER- BCs had a tendency (higher grade and 5 years-MFS $[p=0.059$ and $\mathrm{p}=0.06$, respectively]) to have a poorer prognosis and were more likely to recur than ER+BCs (Additionnal file 1-Table S9B).

\section{Discussion}

We used high-resolution aCGH and DNA microarrays to define the genome and gene expression profiles of BCs with 17q12-q21-amplification. Results concerning cell lines are given for information to the scientific community.

At this stage, we would not discuss any relation between ERBB2 amplicon size and resistance to trastuzumab because of small numbers.

\section{Genomic alterations of ERBB2-amplified tumors}

We identified 18 regions targeted by CNAs in ERBB2amplified BCs. As expected, the most frequent encompassed the region of $E R B B 2$-amplification previously defined [17,37] and included NEUROD2, PPP1R1B, STARD3, TCAP, PNMT, PERLD1, ERBB2, C17ORF37, GRB7 and IKZF3/ZNFN1A3 17q12 genes (>85\% of 17q12-q21-amplified samples) (Additionnal file 1-Table S5). ERBB2-C17orf37-GRB7 was the core region systematically included in all 17q12-q21-amplified samples.

We noted that 8q24.1, 11q13.4-q14.1, 14q11.1-q11.2, 17q21.1-q21.2 and 19q12 regions of amplification were associated with ERBB2-amplified BCs. Some of these regions were previously reported co-amplified in breast cancers [1] (Additionnal file 1-Table S6A). A recent study [47] showed correlations between the presence of such amplicons and molecular subtypes in grade 3 invasive ductal BCs (Additionnal file 1-Table S6A) suggesting that (i) the two amplified subregions within 8q24.1 amplifications (with a frequency of $50 \%$ and $21 \%$ ) coud be associated with basal and non-basal subtypes, respectively; (ii) the 11q13.4-q14.1 amplification (with a frequency of $15 \%$ ) could be associated exclusively with the luminal subtype; (iii) the 14q12, 14q12-q13.1 and 14q23.2-q23.3 amplifications (with an identical 
frequency of $12 \%$ ) coud be associated exclusively with the ERBB2 subtype; (iv) the 17q21.1-q21.2 amplification (with a frequency of 100\%) coud be associated exclusively with the ERBB2 subtype. In contrast, for other 17q amplicons (17q21.32, 17q21.32-q22, 17q23.1q23.2 and $17 \mathrm{q} 23.3$ ) we did not found any association with ERBB2-amplified tumors; (v) the two amplified subregions within 19q12 amplifications (with frequencies of $12 \%$ and $16 \%$, respectively) coud be associated exclusively with the basal subtype.

We showed a genomic heterogeneity of ERBB2-amplified BCs with respect to with ER+ and ER-status. The genomic profiles of ER+ and ER-ERBB2-amplified tumors were previously reported [18]. Gains of 17q23q24 and losses of $1 \mathrm{p} 39,1 \mathrm{p} 36,1 \mathrm{p} 35,1 \mathrm{p} 32,7 \mathrm{q} 21-\mathrm{q} 22$, 7q34, 7q36.1-q36.3, 9p21.3, and 11q13.5 were more frequent in ER+ cases while gain of 5p15-p12 was associated with ER-cancers. None of these regions was observed similarly altered in our study (Additionnal file 1-Table S6A).

We identified 37 genes whose expression levels were deregulated in proportion to CNA. Some of these genes were similarly found in previous studies $[1,48](S Q L E$, KIAA0196, STARD3, PERLD1, ERBB2, GRB7, CCNE1). In ER+ERBB2-amplified BCs, only PVT1 was commonly found with this study [1]. Similarly, 24 genes (65\%) from another previous study [38] were common with our candidates (Additionnal file 1-Table S6A). Seventeen (SQLE, DDX52, MRPL45, SOCS7, PSMB3, PIP4K2B, CCDC49, LASP1, FBXL20, MED1, STARD3, PERLD1, ERBB2, C17orf37, GRB7, RAPGEFL1, and CCNE1) and three (KIAA0196, RSF1, INTS4) were associated with ERBB2 and luminal molecular subtypes, respectively; KCTD21 and PERLD1 were associated with both ERBB2 and luminal molecular subtypes. MAL2, WIPF2 and CDC6 were not associated with any specific molecular subtype [38].

The difference in the number of genes found in our study compared to previous studies $[1,38,47,48]$ could be explained by the high resolution aCGH $244 \mathrm{~K}$ we used (whereas 2464 BAC arrays [OncoBAC array] and $32 \mathrm{~K}$ BAC arrays were previously used [[1] and $[38,47,48]$, respectively]) and by integrating gene level with gene expression analysis.

Within the 17q12-q21 region, amplification of $E R B B 2$, STARD3, TCAP, PNMT, PERLD1, C17orf37, GRB7, GSDML, PSMD3 and THRAP4 genes have been reported to correlate with gene expression $[1,15,28,36]$. Amplification and overexpression of other genes (such as GRB7, C17orf37 and STARD3) of the 17q12 region could contribute to tumor growth $[18,19]$. C17orf37 open reading frame encodes a $12-\mathrm{kDa}$ protein of unknown function. C17ORF37 protein expression is linked with ERBB2-amplification in most cases, however, it has also been observed in breast carcinomas that do not overexpress ERBB2, and particularly in early stage and infiltrating lobular carcinomas that typically do not overexpress ERBB2 [49]. This suggests that C17ORF37 could represent an additional target for cancer therapy. Growth factor receptor-bound protein 7 (GRB7) is an adaptor-type signaling protein that binds to a variety of cell surface receptor tyrosine kinases including EGFR and ERBB2 [50] to mediate downstream signaling pathways. GRB7 may facilitate ERBB2-mediated signal transduction and tumor formation [51] and has been suggested as a therapeutic target [19].

Seventeen other regions were affected by CNAs with a lower frequency in ERBB2-amplified tumors. Some of them have been found involved in mammary carcinogenesis. Loss of 4p16.3 (Additionnal file 1-Table S6A) was telomeric to the deleted $\mathrm{R} 4$ region located between D4S43 and D4S127 (4p16.3) previously observed in breast carcinomas [52]. It included CTBP1, whose decreased expression has been associated with migratory, invasive potential of melanoma cells [53]. However, we did not observe downregulated CTBP1 expression in proportion to the deletion of this region. The $4 \mathrm{q} 13.3$ gain/amplification targeted 20 genes, including those encoding EGFR ligands EPEG, EREG, AREG and BTC, which could play a critical role in oncogenesis [54]. Loss of 8 p23.3, a region affected by deletion in both breast and pancreatic cell lines [55] targeted 10 genes including ARHGEF10, a potential tumor suppressor [55]. However, this gene did not show downregulated expression in proportion to copy number loss.

Gain and amplification of 8q23.3-q24.21 targeted 31 genes. This region delimited from centromere to telomere by TRPS1 and PVT1 contains MYC, two colorectal cancer risk loci, rs16892766 (8q23.3) [56] and rs6983267 (8q24.21), and one breast cancer risk locus rs13281615 (8q24.21) [57]. rs6983267 is a good candidate for a multicancer susceptibility marker [58]. A strong association for rs13281615 was observed for ER+, PR+, and low grade breast tumors [57]. To date, no relationship has been reported between the presence of these loci and the 8q23.3-q24.21 amplification. Coamplification of $M Y C$ and PVT1 seem to correlate with rapidly growing and progressive breast cancer and has been associated with poor outcome in postmenopausal or ERBB2-positive BC patients [59]. Only C8orf53, MAL2, LOC286052, SQLE and KIAA0196 were upregulated in proportion to copy number gain or amplification of the 8q23.3-q24.21 region in the ERBB2-amplified tumors. The MAL2 gene was previously found amplified and overexpressed in breast and other cancers, yet the significance of this is unknown. $S Q L E$ overexpression was found in high-risk ER+ stage I/II BCs [60] but SQLE mRNA overexpression was not different in ER+ and ER- ERBB2-amplified tumors. 
Amplification of 8q24.11-13 (THRAP6, DCC1, SQLE, SPG8) and 11q14.1 (NDUFC2, ALG8, USP35) have been associated with poor prognosis in a novel subtype of high-grade ER-tumors [36]. Within 11q13.5-q14.1, RSF1, INTS4 and KCTD21 were upregulated in proportion to copy number gain/amplification in the ERBB2amplified tumors. RSF1, a chromatin-remodeling gene, was identified as a potential oncogene in ovarian serous carcinoma [61].

Within 19q12, CCNE1 was upregulated in proportion to copy number gain or amplification. CCNE1 expression in breast cancer cells has been associated with ERstatus, ERBB2 expression, high tumor grade and high proliferation index [62]. Breast cancer-associated variants have been found in four cell cycle genes including CCNE1 rs997669 [63].

\section{ER- and ER + ERBB2-amplified breast tumors}

Expression profiling studies $[11,64]$ have also suggested that ERBB2-amplified BCs constitute a heterogeneous group that could be subdivided according to ER status: $\mathrm{ER}+E R B B 2$-amplified $\mathrm{BCs}$ fall into the luminal $\mathrm{B}$ cluster; and ER-ERBB2-amplified BCs constitute the actual ERBB2-like subtype.

Specific genetic aberrations and expression are indeed characteristic of ER+ and ER- ERBB2 BCs. Upregulated ESR1, GATA3, ERBB4, TFF1 and TFF3 gene expression was associated with ER+ERBB2-amplified tumors. These genes are typically associated with the luminal subtype, suggesting that the ER+ERBB2-amplified tumors could be a branch of the luminal tumors and could share the same progenitor. Only TRPS1 and PVT1 were identified as candidate oncogenes in ER+ERBB2amplified tumors. TRPS1 encodes a zinc finger transcription factor widely expressed in human tissues and overexpressed in BCs [65]. PVT1 is most likely a noncoding RNA that acts independently of $M Y C$ and, when amplified and overexpressed, increases proliferation and inhibits apoptosis [66]. Seven miRNAs cover PVT1 [67] and could play a role in mammary oncogenesis.

The ER-ERBB2-amplified samples were mainly ERBB2-like (88\%) (Additionnal file 1-Table S9B) and upregulated IGF2R, GATA6, TGFA and EGFR. The canonical WNT/ $\beta$-catenin signaling pathway was associated with ER-ERBB2-amplified tumors. $\beta$-catenin is a substrate of ERBB2 kinase. Geldanamycin could be included in the panel of potential therapeutic tools because it destabilizes ERBB2 tyrosine kinase and suppresses $\mathrm{WNT} / \beta$-catenin signaling in ERBB2-overexpressing cells [68].

\section{IBCs and NIBCs with ERBB2-amplification}

We found that the size of $E R B B 2$ amplicon is smaller in IBC than in NIBC and that this difference is independent of the ER status. Perhaps the rapid evolution of IBC prevents the construction of large amplicons.

Twelve genes were deregulated in ERBB2-amplified IBCs. Ten of them (SNIP, MLLT6, CISD3, PCGF2, PSMB3, PIP4K2B, FBXL20, STARD3, GRB7 and RARA) are located within the 17q12-q21-amplicon suggesting that this region has a strong influence on the IBC phenotype in ERBB2-amplified BCs. Some of the 10 downregulated genes are potential tumor suppressor genes. The SNIP protein is tyrosine phosphorylated upon integrin-dependent adhesion or EGF treatment, with a potential role as a downstream effector of cell matrix and growth factor signaling that suppresses tumorigenic properties of breast cancer cells [69]. PCGF2 is a polycomb protein that could act as a tumor suppressor [70].

\section{Markers and targets in ERBB2-amplified BCs}

The response of $E R B B 2$-amplified $\mathrm{BCs}$ to anthracyclines may be influenced by the presence of TOP $2 A$ in the 17q12-q21-amplicon [20,21,37]. Although TOP2A amplification was described as a discriminatory feature between ER+ and ER-ERBB2-amplified BCs [48] we were not able to confirm this result because the statistical analysis was not applicable to our data. (Data not shown).

IGF1R+ or EGFR+ERBB2-amplified tumors were all ERBB2+ while IGF1R and EGFR were rarely coexpressed. Previous studies have suggested that interactions among families of growth factor receptors enhance the malignant behavior of tumor cells [71]. Furthermore, cross-talk between IGF1R and EGFR or ERBB2 has been implicated in the development of resistance to EGFR and ERBB2 inhibitors [46]. FOXA1 was frequently coexpressed with ERBB2 in ERBB2-amplified tumors. FOXA1 is essential for optimal expression of half of ERrelated genes. FOXA1 expression correlates with luminal A subtype and good prognosis [72]. We did not find any association between FOXA1 expression and the outcome of patients with ERBB2-amplified tumors.

\section{Conclusions}

Our study shows that ERBB2 BCs are heterogeneous with respect to clinical, immunohistochemical and molecular factors and identifies features that may be useful in the design of therapeutical approaches of these poor prognosis cancers.

\section{Additional material}

$$
\begin{aligned}
& \text { Additionnal file 1: Supplementary Tables. Table S1 - Clinical and } \\
& \text { histological features of the } 54 \text { profiled ERBB2-amplified breast tumors. } \\
& \text { Table S2 - Proteins tested by IHC: antibodies and experimental } \\
& \text { conditions. Table S3 - Clinical and histological features of the two aCGH- } \\
& \text { clustered ERBB2-amplified tumor groups defined through the whole } \\
& \text { genome. Table S4 - Clinical and histological features of the two aCGH- }
\end{aligned}
$$


clustered ERBB2-amplified tumor groups defined through the [AATFSTAT3] genomic segment. Table S5 - Definition of the ERBB2 amplicon score. Table S6A - Significant altered regions found in the 54 samples harboring the 17q12-q21-amplification (defined by the score index with a threshold of $10^{-3}$ ). Table S6B - Gene expression deregulation frequencies of genes included in ERBB2-amplicon. Table S7A - Integrated genome analysis of ER- and ER+ ERBB2-amplified tumors. Table S7BClinical and histological features of the two clustered ERBB2-amplified tumor groups defined using gene expression data. Table S7C - Genes with expression significantly different in ER- and ER+ ERBB2-amplified tumors. Table S7D - Canonical pathways associated with ER+ and ERexpression signature in ERBB2-amplified BCS. Table S7E - Regions significantly altered by CNA in ERBB2-amplified IBC and NIBC. Table S8 Transversal analysis of ERBB2-amplified BCs. Table S9A - Clinical features and protein expression analysis of ERBB2-amplified BCs. Table S9B Clinical features and protein expression analysis of ER+ and ER- ERBB2amplified BCs.

\section{Additionnal file 2: Supplementary Material.}

Additionnal file 3: Figure S1: Genomic profiles of chromosome 17 in ERBB2-amplified primary breast tumors and breast cancer cell lines. A-C - Regional 17q12-q21 amplification centered on the ERBB2 locus observed in the 54 studied BCs. S1A and S1B-C show genomic profiles of chromosome 17 established with $\mathrm{CGH}$ analytics ${ }^{\circledast}$ software (Agilent Technologies) in IBC and NIBC samples, respectively. The 17q12q21 amplification ( $\log _{2}$ ratio $>1$ ) was found as single abnormality or associated with other various copy number aberrations along chromosome 17. The arrow indicates the 17q12-q21-amplicon centered on the ERBB2 locus. D - Regional 17q12-q21-amplification centered on the ERBB2 locus observed in the 14 studied breast cancer cell lines. Genomic profiles of chromosome 17 were established as defined in Additionnal file 3-Figures S1A-C.

Additionnal file 4: Figure S2: Whole-genome expression profiling of ERBB2-amplified BCs. A - Hierarchical clustering of 51 samples and 13,114 genes/ESTs with significant variation in mRNA expression level across the samples. Each row of the data matrix represents a gene and each column represents a sample. Expression levels are depicted according to the color scale shown at the bottom. Red and green indicate expression levels respectively above and below the median. The magnitude of deviation from the median is represented by the color saturation. The dendrogram of samples (above matrixes) represents overall similarities in gene expression profiles and is zoomed in B. B Dendrograms of samples. Top, Two large groups of tissue samples (designated I to II) are evidenced by clustering and delimited by the orange solid vertical line (see also Additionnal file 1-Table S7B). Below the dendrogram, Below the dendrogram, from the top to the bottom, name of tumors are given and the two first rows indicate their ER and IGF1R status (black square, ER+ or IGF1R+; white square, ER- or IGF1R-) of patients, while the last row indicates the molecular subtypes. The third row indicates the gene expression molecular subtypes as previously defined [13] using specific colored squares (luminal A: dark blue; luminal B: sky blue; basal: red; ERBB2-like: pink; normal-like: green and not assigned: white).

Additionnal file 5: Figure S3: Canonical pathways associated with ER+ and ER- ERBB2-amplified BCs. Histograms show canonical pathways associated with either ER+ or ER- ERBB2-amplified BCs. Established by Ingenuity ${ }^{\oplus}$ pathways analysis software, they show relevant proteins (Additionnal file 1-Table S7D) encoded by genes associated with the ER+/ER-ERBB2-amplified BCs molecular signature (Additionnal file 1Table S7C). Color codes and corresponding legends are indicated in the box located to the left at the top of the figure.

\section{Acknowledgements}

We thank C. Chabannon for institutional biobanking. This work was supported by Inserm, Institut Paoli-Calmettes, and grants from the Ligue Nationale Contre le Cancer (LNCC) (Label 2007-2009) and Institut National du Cancer (PL 2006 and ACl 2007). F.S. is supported by a fellowship from the French Government and I. B. by a fellowship from the Algerian Government.

\section{Author details}

${ }^{1}$ Marseille Cancer Research Center, UMR891 Inserm, Institut Paoli-Calmettes, Department of Molecular Oncology, Marseille, France. ${ }^{2}$ Department of BioPathology, Institut Paoli-Calmettes, Marseille, France. ${ }^{3}$ Department of Medical Oncology, Institut Paoli-Calmettes, Marseille, France. ${ }^{4}$ Université de la Méditerranée, Marseille, France. ${ }^{5}$ Department of Medical Oncology, Salah Azaiz Institute, Tunis, Tunisia.

\section{Authors' contributions}

All authors read and approved the final manuscript. FS, IB and JA did the genomic profiling and data analysis. $\mathrm{PF}, \mathrm{Cl}$, and JB did the transcriptome experiments and data analysis. IB, SR, ABH and JJ did the immunohistochemistry and data analysis. ECJ and $J J$ are pathologists and were responsible for clinical features collections. PV, CT, FBA and FB are physicians in charge of the patients. $F B, D B$, and $M C$ did project planning, integrated data analysis and manuscript writing.

\section{Competing interests}

The authors declare that they have no competing interests.

Received: 23 February 2010 Accepted: 8 October 2010 Published: 8 October 2010

\section{References}

1. Chin K, DeVries S, Fridlyand J, Spellman PT, Roydasgupta R, Kuo WL, Lapuk A, Neve RM, Qian Z, Ryder T, Chen F, Feiler H, Tokuyasu T, Kingsley C, Dairkee S, Meng Z, Chew K, Pinkel D, Jain A, Ljung BM, Esserman L, Albertson DG, Waldman FM, Gray JW: Genomic and transcriptional aberrations linked to breast cancer pathophysiologies. Cancer Cell 2006, 10:529-541.

2. Letessier A, Sircoulomb F, Ginestier C, Cervera N, Monville F, Gelsi-Boyer V, Esterni B, Geneix J, Finetti P, Zemmour C, Viens P, Charafe-Jauffret E, Jacquemier J, Birnbaum D, Chaffanet M: Frequency, prognosis impact and subtype association of $8 p 12,8 q 24,11 q 13,12 p 13,17 q 12$ and $20 q 13$ amplifications in breast cancers. BMC Cancer 2006, 6:245.

3. Adélaïde J, Finetti P, Bekhouche I, Repellini L, Geneix J, Sircoulomb F, Charafe-Jauffret E, Cervera N, Desplans J, Parzy D, Schoenmakers E, Viens P, Jacquemier J, Birnbaum D, Bertucci F, Chaffanet M: Integrated profiling of basal and luminal breast cancers. Cancer Res 2007, 67:11565-11575.

4. Konecny GE, Pegram MD, Venkatesan N, Finn R, Yang G, Rahmeh M, Untch M, Rusnak DW, Spehar G, Mullin RJ, Keith BR, Gilmer TM, Berger M, Podratz KC, Slamon DJ: Activity of the dual kinase inhibitor lapatinib (GW572016) against HER-2-overexpressing and trastuzumab-treated breast cancer cells. Cancer Res 2006, 66:1630-639.

5. Shepard HM, Jin P, Slamon DJ, Pirot Z, Maneval DC: Herceptin. Handb Exp Pharmacol 2008, 181:183-219.

6. Piccart-Gebhart MJ, Procter M, Leyland-Jones B, Goldhirsch A, Untch M, Smith I, Gianni L, Baselga J, Bell R, Jackisch C, Cameron D, Dowsett M, Barrios CH, Steger G, Huang CS, Andersson M, Inbar M, Lichinitser M, Láng I, Nitz U, Iwata H, Thomssen C, Lohrisch C, Suter TM, Rüschoff J, Suto T, Greatorex V, Ward C, Straehle C, McFadden E, Dolci MS, Gelber RD, Herceptin Adjuvant (HERA) Trial Study Team: Trastuzumab after adjuvant chemotherapy in HER2-positive breast cancer. N Engl J Med 2005, 353:1659-1672.

7. Nahta R, Yu D, Hung MC, Hortobagyi GN, Esteva FJ: Mechanisms of disease: understanding resistance to HER2-targeted therapy in human breast cancer. Nat Clin Pract Oncol 2006, 3:269-280.

8. Ginestier $C$, Adélaïde J, Gonçalvès $A$, Repellini L, Sircoulomb F, Letessier A, Finetti P, Geneix J, Charafe-Jauffret E, Bertucci F, Jacquemier J, Viens $P$, Birnbaum D: ERBB2 phosphorylation and trastuzumab sensitivity of breast cancer cell lines. Oncogene 2007, 26:7163-9.

9. Berns K, Horlings HM, Hennessy BT, Madiredjo M, Hijmans EM, Beelen K, Linn SC, Gonzalez-Angulo AM, Stemke-Hale K, Hauptmann M, Beijersbergen RL, Mills GB, van de Vijver MJ, Bernards R: A functional genetic approach identifies the PI3K pathway as a major determinant of trastuzumab resistance in breast cancer. Cancer Cell 2007, 12:395-402.

10. Ginestier C, Charafe-Jauffret E, Penault-Llorca F, Geneix J, Adélaïde J, Chaffanet M, Mozziconacci MJ, Hassoun J, Viens P, Birnbaum D, Jacquemier J: Comparative multi-methodological measurement of ERBB2 status in breast cancer. J Pathol 2004, 202:286-298. 
11. Sorlie T, Tibshirani R, Parker J, Hastie T, Marron JS, Nobel A, Deng S, Johnsen H, Pesich R, Geisler S, Demeter J, Perou CM, Lønning PE, Brown PO, Børresen-Dale AL, Botstein D: Repeated observation of breast tumor subtypes in independent gene expression data sets. Proc Natl Acad Sci USA 2003, 100:8418-8423.

12. Bertucci F, Borie N, Ginestier C, Groulet A, Charafe-Jauffret E, Adélaïde J, Geneix J, Bachelart L, Finetti P, Koki A, Hermitte F, Hassoun J, Debono S, Viens $P$, Fert $V$, Jacquemier J, Birnbaum D: Identification and validation of an ERBB2 gene expression signature in breast cancers. Oncogene 2004, 23:2564-2575.

13. Hu Z, Fan C, Oh DS, Marron JS, He X, Qaqish BF, Livasy C, Carey LA, Reynolds E, Dressler L, Nobel A, Parker J, Ewend MG, Sawyer LR, Wu J, Liu Y, Nanda R, Tretiakova M, Ruiz Orrico A, Dreher D, Palazzo JP, Perreard L, Nelson E, Mone M, Hansen H, Mullins M, Quackenbush JF, Ellis MJ, Olopade OI, Bernard PS, Perou CM: The molecular portraits of breast tumors are conserved across microarray platforms. BMC Genomics 2006, 7:96.

14. Rouzier R, Perou CM, Symmans WF, Ibrahim N, Cristofanilli M, Anderson K, Hess KR, Stec J, Ayers M, Wagner P, Morandi P, Fan C, Rabiul I, Ross JS, Hortobagyi GN, Pusztai L: Breast cancer molecular subtypes respond differently to preoperative chemotherapy. Clin Cancer Res 2005, 11:5678-5685.

15. Parker JS, Mullins M, Cheang MC, Leung S, Voduc D, Vickery T, Davies S, Fauron C, He X, Hu Z, Quackenbush JF, Stijleman IJ, Palazzo J, Marron JS, Nobel AB, Mardis E, Nielsen TO, Ellis MJ, Perou CM, Bernard PS: Supervised risk predictor of breast cancer based on intrinsic subtypes. J Clin Oncol 2009, 27:1160-1167.

16. Sørlie T, Perou CM, Tibshirani R, Aas T, Geisler S, Johnsen H, Hastie T, Eisen MB, van de Rijn M, Jeffrey SS, Thorsen T, Quist H, Matese JC, Brown PO, Botstein D, Eystein Lønning P, Børresen-Dale AL: Gene expression patterns of breast carcinomas distinguish tumor subclasses with clinical implications. Proc Natl Acad Sci USA 2001, 98:10869-10874.

17. Kauraniemi $P$, Kallioniemi A: Activation of multiple cancer-associated genes at the ERBB2 amplicon in breast cancer. Endocr Relat Cancer 2006, 13:39-49.

18. Kao J, Pollack JR: RNA interference-based functional dissection of the $17 q 12$ amplicon in breast cancer reveals contribution of coamplified genes. Genes Chromosomes Cancer 2006, 45:761-769.

19. Pero SC, Shukla GS, Cookson MM, Flemer S Jr, Krag DN: Combination treatment with Grb7 peptide and doxorubicin or trastuzumab (Herceptin) results in cooperative cell growth inhibition in breast cancer cells. Br J Cancer 2007, 96:1520-1525.

20. Pritchard Kl, Messersmith H, Elavathil L, Trudeau M, O'Malley F, DhesyThind B: HER-2 and topoisomerase $\|$ as predictors of response to chemotherapy. J Clin Oncol 2008, 26:736-744.

21. Slamon DJ, Press MF: Alterations in the TOP2A and HER2 Genes: Association With Adjuvant Anthracycline Sensitivity in Human Breast Cancers. J Natl Cancer Inst 2009, 101:615-618.

22. Adélaïde J, Finetti $P$, Charafe-Jauffret $E$, Wicinski J, Jacquemier J, Sotiriou C, Bertucci F, Birnbaum D, Chaffanet M: Absence of ESR1 amplification in a series of breast cancers. Int J Cancer 2008, 123:2970-2972.

23. [http://www.atcc.org/]

24. [http://www.cancer.med.umich.edu/breast_cell/production].

25. Neve RM, Chin K, Fridlyand J, Yeh J, Baehner FL, Fevr T, Clark L, Bayani N, Coppe JP, Tong F, Speed T, Spellman PT, DeVries S, Lapuk A, Wang NJ, Kuo WL, Stilwell JL, Pinkel D, Albertson DG, Waldman FM, McCormick F, Dickson RB, Johnson MD, Lippman M, Ethier S, Gazdar A, Gray JW: A collection of breast cancer cell lines for the study of functionally distinct cancer subtypes. Cancer Cell 2006, 10:515-527.

26. Theillet C, Adelaïde J, Louason G, Bonnet-Dorion F, Jacquemier J, Adnane J, Longy M, Katsaros D, Sismondi P, Gaudray P, Birnbaum D: FGFRI and PLAT genes and DNA amplification at 8 p12 in breast and ovarian cancers. Genes Chromosomes Cancer 1993, 7:219-226.

27. Beroukhim R, Getz G, Nghiemphu L, Barretina J, Hsueh T, Linhart D, Vivanco I, Lee JC, Huang JH, Alexander S, Du J, Kau T, Thomas RK, Shah K, Soto H, Perner S, Prensner J, Debiasi RM, Demichelis F, Hatton C, Rubin MA, Garraway LA, Nelson SF, Liau L, Mischel PS, Cloughesy TF, Meyerson M, Golub TA, Lander ES, Mellinghoff IK, Sellers WR: Assessing the significance of chromosomal aberrations in cancer: methodology and application to glioma. Proc Natl Acad Sci USA 2007, 104:20007-20012.
28. Bertucci F, Finetti P, Cervera N, Maraninchi D, Viens P, Birnbaum D: Gene expression profiling and clinical outcome in breast cancer. OMICS 2006, 10:429-443, Winter.

29. Eisen MB, Spellman PT, Brown PO, Botstein D: Cluster analysis and display of genome-wide expression patterns. Proc Natl Acad Sci USA 1998, 95:14863-14868.

30. Suzuki R, Shimodaira H: Pvclust: an R package for assessing the uncertainty in hierarchical clustering. Bioinformatics 2006, 22:1540-1542.

31. [http://www.ingenuity.com/].

32. Ginestier C, Charafe-Jauffret E, Bertucci F, Eisinger F, Geneix J, Bechlian D, Conte N, Adélaïde J, Toiron Y, Nguyen C, Viens P, Mozziconacci MJ, Houlgatte R, Birnbaum D, Jacquemier J: Distinct and complementary information provided by use of tissue and DNA microarrays in the study of breast tumor markers. Am J Pathol 2002, 161:1223-1233.

33. Oyama T, Ishikawa Y, Hayashi M, Arihiro K, Horiguchi J: The Effects of Fixation, Processing and Evaluation Criteria on Immunohistochemical Detection of Hormone Receptors in Breast Cancer. Breast Cancer 2007 14:182-188.

34. Pollack JR, Sørlie T, Perou CM, Rees CA, Jeffrey SS, Lonning PE, Tibshirani R, Botstein D, Børresen-Dale AL, Brown PO: Microarray analysis reveals a major direct role of DNA copy number alteration in the transcriptional program of human breast tumors. Proc Natl Acad Sci USA 2002, 99:12963-12968.

35. Chin SF, Wang Y, Thorne NP, Teschendorff AE, Pinder SE, Vias M, Naderi A, Roberts I, Barbosa-Morais NL, Garcia MJ, Iyer NG, Kranjac T, Robertson JF, Aparicio S, Tavaré S, Ellis I, Brenton JD, Caldas C: Using array-comparative genomic hybridization to define molecular portraits of primary breast cancers. Oncogene 2007, 26:1959-1970.

36. Chin SF, Teschendorff AE, Marioni JC, Wang Y, Barbosa-Morais NL, Thorne NP, Costa JL, Pinder SE, van de Wiel MA, Green AR, Ellis IO, Porter PL, Tavaré S, Brenton JD, Ylstra B, Caldas C: High-resolution aCGH and expression profiling identifies a novel genomic subtype of ER negative breast cancer. Genome Biol 2007, 8:R215

37. Arriola E, Marchio C, Tan DS, Drury SC, Lambros MB, Natrajan R, RodriguezPinilla SM, Mackay A, Tamber N, Fenwick K, Jones C, Dowsett M, Ashworth A, Reis-Filho JS: Genomic analysis of the HER2/TOP2A amplicon in breast cancer and breast cancer cell lines. Lab Invest 2008, 88: 491-503.

38. Natrajan R, Weigelt B, Mackay A, Geyer FC, Grigoriadis A, Tan DS, Jones C, Lord CJ, Vatcheva R, Rodriguez-Pinilla SM, Palacios J, Ashworth A, ReisFilho JS: An integrative genomic and transcriptomic analysis reveals molecular pathways and networks regulated by copy number aberrations in basal-like, HER2 and luminal cancers. Breast Cancer Res Treat 2009.

39. Naylor TL, Greshock J, Wang Y, Colligon T, Yu QC, Clemmer V, Zaks TZ, Weber BL: High resolution genomic analysis of sporadic breast cancer using array-based comparative genomic hybridization. Breast Cancer Res 2005, 7:R1186-1198.

40. Ademuyiwa FO, Thorat MA, Jain RK, Nakshatri $H$, Badve S: Expression of Forkhead-box protein A1, a marker of luminal A type breast cancer, parallels low Oncotype DX 21-gene recurrence scores. Mod Pathol 2010, 23:270-275.

41. Nakshatri H, Badve S: FOXA1 in breast cancer. Expert Rev Mol Med 2009, 11:e8.

42. Hudelist G, Köstler WJ, Czerwenka K, Kubista E, Attems J, Müller R, Gschwantler-Kaulich D, Manavi M, Huber I, Hoschützky H, Zielinski CC, Singer CF: Her-2/neu and EGFR tyrosine kinase activation predict the efficacy of trastuzumab-based therapy in patients with metastatic breast cancer. Int J Cancer 2006, 118:1126-1134.

43. Johnston S, Trudeau M, Kaufman B, Boussen H, Blackwell K, LoRusso P, Lombardi DP, Ben Ahmed S, Citrin DL, DeSilvio ML, Harris J, Westlund RE, Salazar V, Zaks TZ, Spector NL: Phase II study of predictive biomarker profiles for response targeting human epidermal growth factor receptor 2 (HER-2) in advanced inflammatory breast cancer with lapatinib monotherapy. J Clin Oncol 2008, 26:1066-1072.

44. Matsubara J, Yamada Y, Hirashima Y, Takahari D, Okita NT, Kato K, Hamaguchi T, Shirao K, Shimada Y, Shimoda T: Impact of insulin-like growth factor type 1 receptor, epidermal growth factor receptor, and HER2 expressions on outcomes of patients with gastric cancer. Clin Cancer Res 2008, 14:3022-3029. 
45. Jin Q, Esteva FJ: Cross-talk between the ErbB/HER family and the type I insulin-like growth factor receptor signaling pathway in breast cancer. J Mammary Gland Biol Neoplasia 2008, 13:485-498.

46. Yamaguchi N, Ito E, Azuma S, Honma R, Yanagisawa Y, Nishikawa A, Kawamura M, Imai J, Tatsuta K, Inoue J, Semba K, Watanabe S: FoxA1 as a lineage-specific oncogene in luminal type breast cancer. Biochem Biophys Res Commun 2008, 365:711-7.

47. Natrajan R, Lambros MB, Rodríguez-Pinilla SM, Moreno-Bueno G, Tan DS, Marchió C, Vatcheva R, Rayter S, Mahler-Araujo B, Fulford LG, Hungermann D, Mackay A, Grigoriadis A, Fenwick K, Tamber N, Hardisson D, Tutt A, Palacios J, Lord CJ, Buerger H, Ashworth A, Reis-Filho JS: Tiling path genomic profiling of grade 3 invasive ductal breast cancers. Clin Cancer Res 2009, 15:2711-2722.

48. Marchiò C, Natrajan R, Shiu KK, Lambros MB, Rodriguez-Pinilla SM, Tan DS, Lord CJ, Hungermann D, Fenwick K, Tamber N, Mackay A, Palacios J, Sapino A, Buerger H, Ashworth A, Reis-Filho JS: The genomic profile of HER2-amplified breast cancers: the influence of ER status. J Pathol 2008, 216:399-407.

49. Evans EE, Henn AD, Jonason A, Paris MJ, Schiffhauer LM, Borrello MA, Smith ES, Sahasrabudhe DM, Zauderer M: C35 (C17orf37) is a novel tumor biomarker abundantly expressed in breast cancer. Mol Cancer Ther 2006, 5:2919-2930.

50. Han DC, Shen TL, Guan JL: The Grb7 family proteins: structure, interactions with other signaling molecules and potential cellular functions. Oncogene 2001, 20:6315-6321.

51. Bai T, Luoh SW: GRB-7 facilitates HER-2/Neu-mediated signal transduction and tumor formation. Carcinogenesis 2008, 29:473-479.

52. Shivapurkar N, Sood S, Wistuba II, Virmani AK, Maitra A, Milchgrub S, Minna JD, Gazdar AF: Multiple regions of chromosome 4 demonstrating allelic losses in breast carcinomas. Cancer Res 1999, 59:3576-3580.

53. Winklmeier A, Poser I, Hoek KS, Bosserhoff AK: Loss of full length CtBP1 expression enhances the invasive potential of human melanoma. BMC Cancer 2009, 9:52.

54. Sanderson MP, Dempsey PJ, Dunbar AJ: Control of ErbB signaling through metalloprotease mediated ectodomain shedding of EGF-like factors. Growth Factors 2006, 24:121-136.

55. Cooke SL, Pole JC, Chin SF, Ellis IO, Caldas C, Edwards PA: High-resolution array CGH clarifies events occurring on $8 p$ in carcinogenesis. BMC Cancer 2008, 8:288.

56. Tomlinson IP, Webb E, Carvajal-Carmona L, Broderick P, Howarth K, Pittman AM, Spain S, Lubbe S, Walther A, Sullivan K, Jaeger E, Fielding S, Rowan A, Vijayakrishnan J, Domingo E, Chandler I, Kemp Z, Qureshi M, Farrington SM, Tenesa A, Prendergast JG, Barnetson RA, Penegar S, Barclay E, Wood W, Martin L, Gorman M, Thomas H, Peto J, Bishop DT, Gray R, Maher ER, Lucassen A, Kerr D, Evans DG, Consortium CORGl, Schafmayer C, Buch S, Völzke H, Hampe J, Schreiber S, John U, Koessler T, Pharoah P, van Wezel T, Morreau H, Wijnen JT, Hopper JL, Southey MC, Giles GG, Severi G, Castellví-Bel S, Ruiz-Ponte C, Carracedo A, Castells A, Consortium EPICOLON, Försti A, Hemminki K, Vodicka P, Naccarati A, Lipton L, Ho JW, Cheng KK, Sham PC, Luk J, Agúndez JA, Ladero JM, de la Hoya M, Caldés T, Niittymäki I, Tuupanen S, Karhu A, Aaltonen L, Cazier JB, Campbell H, Dunlop MG, Houlston RS: A genome-wide association study identifies colorectal cancer susceptibility loci on chromosomes 10p14 and 8q23.3. Nat Genet 2008, 40:623-630.

57. Garcia-Closas M, Hall P, Nevanlinna H, Pooley K, Morrison J, Richesson DA, Bojesen SE, Nordestgaard BG, Axelsson CK, Arias Jl, Milne RL, Ribas G, González-Neira A, Benítez J, Zamora P, Brauch H, Justenhoven C, Hamann U, Ko YD, Bruening T, Haas S, Dörk T, Schürmann P, Hillemanns $P$, Bogdanova N, Bremer M, Karstens JH, Fagerholm R, Aaltonen K, Aittomäki K, von Smitten K, Blomqvist C, Mannermaa A, Uusitupa M, Eskelinen M, Tengström M, Kosma VM, Kataja V, Chenevix-Trench G, Spurdle AB, Beesley J, Chen X, Australian Ovarian Cancer Management Group, Kathleen Cuningham Foundation Consortium For Research Into Familial Breast Cancer, Devilee P, van Asperen CJ, Jacobi CE, Tollenaar RA, Huijts PE, Klijn JG, Chang-Claude J, Kropp S, Slanger T, Flesch-Janys D, Mutschelknauss E, Salazar R, Wang-Gohrke S, Couch F, Goode EL, Olson JE, Vachon C, Fredericksen ZS, Giles GG, Baglietto L, Severi G, Hopper JL, English DR, Southey MC, Haiman CA, Henderson BE, Kolonel LN, Le Marchand L, Stram DO, Hunter DJ, Hankinson SE, Cox DG, Tamimi R, Kraft P, Sherman ME, Chanock SJ, Lissowska J, Brinton LA, Peplonska B, Klijn JG, Hooning MJ, Meijers-Heijboer H, Collee JM, van den Ouweland A,
Uitterlinden AG, Liu J, Lin LY, Yuqing L, Humphreys K, Czene K, Cox A, Balasubramanian SP, Cross SS, Reed MW, Blows F, Driver K, Dunning A, Tyrer J, Ponder BA, Sangrajrang S, Brennan P, McKay J, Odefrey F, Gabrieau V, Sigurdson A, Doody M, Struewing JP, Alexander B, Easton DF, Pharoah PD: Heterogeneity of breast cancer associations with five susceptibility loci by clinical and pathological characteristics. PLOS Genet 2008, 4:e1000054.

58. Wokolorczyk D, Gliniewicz B, Sikorski A, Zlowocka E, Masojc B, Debniak T, Matyjasik J, Mierzejewski M, Medrek K, Oszutowska D, Suchy J, Gronwald J, Teodorczyk U, Huzarski T, Byrski T, Jakubowska A, Górski B, van de Wetering T, Walczak S, Narod SA, Lubinski J, Cybulski C: A range of cancers is associated with the rs6983267 marker on chromosome 8. Cancer Res 2008, 68:9982-9986.

59. Borg A, Baldetorp B, Fernö M, Olsson H, Sigurdsson H: c-myc amplification is an independent prognostic factor in postmenopausal breast cancer. Int J Cancer 1992, 51:687-691.

60. Helms MW, Kemming D, Pospisil H, Vogt U, Buerger H, Korsching E, Liedtke C, Schlotter CM, Wang A, Chan SY, Brandt BH: Squalene epoxidase, located on chromosome $8 \mathrm{q} 24.1$, is upregulated in $8 \mathrm{q}+$ breast cancer and indicates poor clinical outcome in stage I and II disease. $\mathrm{Br} J$ Cancer 2008, 99:774-780.

61. Shih leM, Sheu JJ, Santillan A, Nakayama K, Yen MJ, Bristow RE, Vang R, Parmigiani G, Kurman RJ, Trope CG, Davidson B, Wang TL: Amplification of a chromatin remodeling gene, Rsf-1/HBXAP, in ovarian carcinoma. Proc Natl Acad Sci USA 2005, 102:14004-14009.

62. Potemski P, Kusinska R, Watala C, Pluciennik E, Bednarek AK, Kordek R: Cyclin E expression in breast cancer correlates with negative steroid receptor status, HER2 expression, tumor grade and proliferation. J Exp Clin Cancer Res 2006, 25:59-64.

63. Driver KE, Song H, Lesueur F, Ahmed S, Barbosa-Morais NL, Tyrer JP, Ponder BA, Easton DF, Pharoah PD, Dunning AM: Studies in Epidemiology and Risks of Cancer Heredity (SEARCH) Team: Association of singlenucleotide polymorphisms in the cell cycle genes with breast cancer in the British population. Carcinogenesis 2008, 29:333-341.

64. Perou CM, Sorlie T, Eisen MB, van de Rijn M, Jeffrey SS, Rees CA, Pollack JR, Ross DT, Johnsen $\mathrm{H}$, Akslen LA, Fluge O, Pergamenschikov A, Williams $\mathrm{C}$, Zhu SX, Lønning PE, Børresen-Dale AL, Brown PO, Botstein D: Molecular portraits of human breast tumours. Nature 2000, 406:747-752.

65. Radvanyi L, Singh-Sandhu D, Gallichan S, Lovitt C, Pedyczak A, Mallo G, Gish K, Kwok K, Hanna W, Zubovits J, Armes J, Venter D, Hakimi J, Shortreed J, Donovan M, Parrington M, Dunn P, Oomen R, Tartaglia J, Berinstein NL: The gene associated with trichorhinophalangeal syndrome in humans is overexpressed in breast cancer. Proc Natl Acad Sci USA 2005, 102:11005-11010.

66. Guan Y, Kuo WL, Stilwell JL, Takano H, Lapuk AV, Fridlyand J, Mao JH, Yu M, Miller MA, Santos JL, Kalloger SE, Carlson JW, Ginzinger DG, Celniker SE, Mills GB, Huntsman DG, Gray JW: Amplification of PVT1 contributes to the pathophysiology of ovarian and breast cancer. Clin Cancer Res 2007, 13:5745-5755.

67. Huppi K, Volfovsky N, Runfola T, Jones TL, Mackiewicz M, Martin SE, Mushinski JF, Stephens R, Caplen NJ: The identification of microRNAs in a genomically unstable region of human chromosome 8q24. Mol Cancer Res 2008, 6:212-221.

68. Wang K, Ma Q, Ren Y, He J, Zhang Y, Zhang Y, Chen W: Geldanamycin destabilizes HER2 tyrosine kinase and suppresses Wnt/beta-catenin signaling in HER2 overexpressing human breast cancer cells. Oncol Rep 2007, 17:89-96.

69. Di Stefano P, Damiano L, Cabodi S, Aramu S, Tordella L, Praduroux A, Piva R, Cavallo F, Forni G, Silengo L, Tarone G, Turco E, Defilippi P: p140Cap protein suppresses tumour cell properties, regulating Csk and Src kinase activity. EMBO J 2007, 26:2843-2855.

70. Lee JY, Jang KS, Shin DH, Oh MY, Kim HJ, Kim Y, Kong G: Mel-18 negatively regulates INK4a/ARF-independent cell cycle progression via Akt inactivation in breast cancer. Cancer Res 2008, 68:4201-4209.

71. Adams TE, McKern NM, Ward CW: Signalling by the type 1 insulin-like growth factor receptor: interplay with the epidermal growth factor receptor. Growth Factors 2004, 22:89-95.

72. Thorat MA, Marchio C, Morimiya A, Savage K, Nakshatri H, Reis-Filho JS, Badve S: Forkhead box A1 expression in breast cancer is associated with luminal subtype and good prognosis. J Clin Pathol 2008 61:327-332. 


\section{Pre-publication history}

The pre-publication history for this paper can be accessed here: http://www.biomedcentral.com/1471-2407/10/539/prepub

doi:10.1186/1471-2407-10-539

Cite this article as: Sircoulomb et al: Genome profiling of ERBB2-

amplified breast cancers. BMC Cancer 2010 10:539.

Submit your next manuscript to BioMed Central and take full advantage of:

- Convenient online submission

- Thorough peer review

- No space constraints or color figure charges

- Immediate publication on acceptance

- Inclusion in PubMed, CAS, Scopus and Google Scholar

- Research which is freely available for redistribution

Submit your manuscript at 